\title{
La Imperial Tarraco. Restauración de los testimonios de la Tarragona romana bajo el franquismo*
}

\author{
The Imperial Tarraco. Restoration of the Roman ruins \\ of Tarragona under the Francisco Franco regime
}

\author{
María Pilar GARCÍA CUETOS \\ Universidad de Oviedo
}

Recibido: 15-V-2014 / Aceptado: 30-VI-2014

Resumen: La ciudad de Tarragona ha establecido una compleja relación con los testimonios de su pasado romano. El régimen franquista utilizó los restos romanos de Tarragona para afianzar su ideología y el periodo del desarrollismo aumentó el valor de esos monumentos para el turismo nacional e internacional. En ese contexto de utilización ideológica y económica de las ruinas romanas por parte del estado franquista, se declaró la ciudad como Conjunto Histórico-Artístico en enero de 1966. Alejandro Ferrant fue arquitecto restaurador de la Cuarta Zona Monumental entre 1944 y 1976 y llevó a cabo los proyectos de restauración de los restos romanos tarraconenses. Estas intervenciones han tenido un papel determinante en su recepción y valoración actuales.

Palabras clave: Restauración monumental, Franquismo, Desarrollismo, Monumentos romanos de Tarragona

ABSTRACT: The city of Tarragona established a complex relationship with the testimonies of its Roman past. The Francisco Franco regime used the Roman ruins of Tarragona to strengthen its ideology as the period called "desarrollis$\mathrm{mo}^{\prime \prime}$, increased the value of the Roman remains for domestic and international tourism. In this context of ideological and economic use of Roman ruins by the Francoist state, the city was declared "conjunto histórico-artístico" (historical site) in January 1966. Alejandro Ferrant was an architect restorer of the Fourth Monumental Zone between 1944 and 1976 and carried the restoration projects of the Roman remains of Tarragona, which have played a decisive role in their reception and current rating.

Keywords: Monumental restoration, Franco dictatorship, Desarrollismo, Roman monuments of Tarragona, Spain

\section{EL DESCUBRIMIENTO DEL PASA- DO ROMANO DE TARRAGONA}

La historia de Tarragona ha determinado su peculiar configuración urbana, na- cida de la suma de diferentes estratos históricos $^{1}$. Sobre los restos de la Tarraco romana,

* Este trabajo se ha elaborado dentro del proyecto de investigación Restauración Monumental y Desarrollis- 
cristalizó la ciudad medieval en torno a la catedral. Las murallas y las condiciones topográficas limitaron la expansión de la urbe hacia el puerto. En el siglo XIV se creó una nueva muralla aprovechando los restos de la fachada del circo romano y en el siglo XVIII se amplió nuevamente el recinto con una fortificación que amparaba los arrabales.

Desde la Edad Media, el pasado romano estuvo presente y fue expresamente buscado. En el siglo XVI los arzobispos Joan de Sessé, Gaspar Cervantes de Gaeta y Antoni Agustí, reunieron una colección arqueológica, instalada en los jardines y huerto del palacio episcopal2. El Libro de las Grandezas y cosas memorables de Tarragona, de Lluis Pons y editado en 1572, se considera el inicio de la investigación historiográfica y arqueológica de la ciudad y en una de las vistas de la misma elaboradas por A. Van der Wyngaerde podemos observar algunos de los restos romanos junto al mar. Pero el problema a la hora de analizar Tarraco ha sido siempre la falta de referencias gráficas y planimétricas que ilustrasen las precisas descripciones de Pons del estado de sus restos y monumentos en el siglo $\mathrm{XVI}^{3}$, limitaciones que han intentado paliarse con el análisis de planos de los

mo en España. 1959-1975, Ref. HAR2011-23918, financiado por el Ministerio de Economía y competitividad y los Fondos Feder y está dedicado a la memoria de Rodolfo García Suárez, de cuya mano visité tantas veces la Tarragona romana.

${ }^{1}$ L. PONS DE ICART, Libro de las grandezas y cosas memorables de la Metropolitana, insigne y famosa ciudad de Tarragona, (1 $1^{\underline{a}}$ ed. Lérida, 1572), Tarragona, 1980, J. M. RECASENS i COMES, La ciutat de Tarragona, Tarragona, 1975, I. ARRAYÁS MORALES, Morfología histórica del territorio de Tarraco (ss. I-III a.C.), Barcelona, 2005, A. JORDÀ FERNÁNDEZ, Història de la ciutat de Tarragona, Tarragona, 2006, pp. 15-32.

${ }^{2}$ J. RUIZ DE ARBULO y R. MAR, "Arqueología y planificación urbana en Tarragona. Tradición historiográfica y realidad actual", en Recuperar la memoria urbana. La Arqueología en la rehabilitación de las ciudades históricas, Tarragona 1997, consultado el 7 de febrero de 2014, URL: http://bib.cervantesvirtual.com/portal/simulacraromae/tarraco/online/f1.pdf

${ }^{3}$ I. NEGERUELA, "Dos importantes planos de Tarragona en el Archivo de Simancas", Quaderns d'història tarraconense, no 5, 1985, pp. 59-75. siglos XVII y XVIII. En esa centuria, se desarrollaron los primeros trabajos de restauración de los testimonios del pasado romano de Tarragona, como los llevados a cabo por Rovira en el arco de Bará, aparecieron los primeros estudios sobre las antigüedades romanas de Tarragona ${ }^{4}$ y en 1784 se iniciaron las excavaciones de carácter anticuarista en el circo romano.

Tras la guerra de la Independencia, que causó importantes daños en la ciudad, en 1844 nacían las Comisiones de Monumentos y se creó la Sociedad Arqueológica Tarraconense, aunque estos organismos de tutela no consiguieron evitar la construcción del nuevo muelle del puerto, que destruyó los restos de uno de los barrios de la ciudad romana. En 1853 fue nombrado Inspector de Antigüedades Buenaventura Hernández Sanahuja (1810-1891), quien desarrolló una intensa labor de tutela e investigación. Entre 1864 y 1868 se creó el Museo Arqueológico y finalmente se publicaron dos obras fundamentales: El indicador arqueológico de Tarragona (1867) y el Catálogo del Museo Arqueológico de Tarragona (1894).

A mediados del siglo XIX, la ciudad experimentó transformaciones que tuvieron una importancia decisiva sobre los restos romanos $^{5}$. Las murallas perdieron su función y en 1859 fueron parcialmente derribadas, intensificándose el crecimiento urbano ${ }^{6}$ partiendo de dos vías que en ese momento estaban configurándose: la calle Unió, trazada antes del derribo de las murallas y que unía la llamada Parte Alta con el puerto, y la calle del Gasómetro. Entre ambas, se trazaron otras nuevas siguiendo una ordenación reticular

${ }^{4}$ J. BOY. Recopilasion sussinta de las antigüedades romanas se allan del tiempo de los emperadores romanos en la ciudad de Taragona y sus sercanías, (1 $1^{\mathrm{a}}$ ed. 1713), Tarragona, 1996; E. FLÓREZ. Antigüedades Tarraconenses, volumen XXIV de la España Sagrada, Madrid 1769 y J. RUIZ DE ARBULO y R. MAR, Op. cit.

${ }^{5}$ C. SALOM i GARRETA, "El auguraculum de la colonia Tárraco: sedes inaugurationis coloniae tarraco", Archivo Español de Arqueología, Vol. 79, 2006, pp. 69-87.

${ }^{6}$ Ibidem, pp. 72-73. 
y se creó la plaza del Progreso (actual Corsini). Este nuevo conjunto urbano se dispuso sobre parte de la trama de la ciudad romana, fundamentalmente el foro y los edificios vinculados al mismo ${ }^{7}$ y su trazado hizo necesario adecuar la topografía previa, de manera que la colina en la que se asentaba la urbs fue rebajada para obtener las rasantes que precisaba la ordenación del nuevo ensanche. Los restos romanos fueron parcialmente arrasados, pero se puso de manifiesto su presencia.

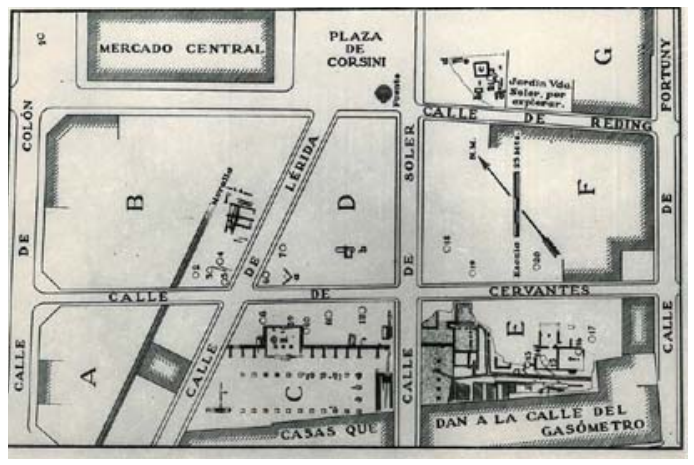

- Fig. 1 Planta del Foro de Tarragona, según Joan Serra y Vilaró (1932). Biblioteca Valenciana. Archivo Alejandro Ferrant Vázquez.

El siglo XX se inició con la declaración monumental de la catedral y el acueducto de les Ferreres (1905), mientras continuaba el proceso de intensa urbanización y transformación de la ciudad. En 1919 se instaló una fábrica de aceites en unos terrenos donde se había documentado anteriormente la existencia de las ruinas del teatro romano, cuyos restos fueron sacados a la luz mediante una excavación de urgencia financiada por el Institut d'Estudis Catalans y llevada a cabo por F. Carbó. Esta investigación aportó hallazgos de importancia, pero generó un debate sobre su legalidad y el traslado de las piezas halladas a Barcelona, sede del Institut, que se resolvió finalmente con la Real Orden de 1921 que dictaminada que debían permanecer en Tarragona. A pesar de su valor, el yacimiento no recibió una declaración monumental que garantizase su tutela y la fábrica permaneció en el lugar. En los años

\footnotetext{
${ }^{7}$ Ibídem, p. 72.
}

cincuenta, el teatro sufrió otro grave daño al construirse un depósito que arrasó la cavea ${ }^{8}$.

El personaje más destacado de la arqueología tarraconense fue Joan Serra i Vilaró (1879-1969) ${ }^{9}$, que desempeñó un papel decisivo en los años veinte y treinta del siglo pasado y llevó a cabo investigaciones muy rigurosas en el descubierto foro de la Colonia y la necrópolis paleocristiana ${ }^{10}$. Su labor fue más allá de la mera investigación y a su iniciativa se debe la conservación in situ de los testimonios de esos dos fundamentales yacimientos tarraconenses. La planta general de las excavaciones de Serra i Vilaró es la única representación gráfica del ensanche con los restos del foro documentados ${ }^{11}$, de forma que podemos leer la superposición de los estratos históricos (Fig.1). Esas labores de investigación se vieron reconocidas por el amparo legal de los restos de la Tarragona romana. En 1926, y a petición de la Comisión de Monumentos, fueron declarados monumentos históricos la iglesia de Santa María del Miracle, el Pretorio Augusto, el arco de Bará y la torre de los Escipiones ${ }^{12}$ y en 1931 y al amparo de la declaración conjunta propiciada por la Segunda República y elaborada por los arquitectos de zona, se reconocieron

${ }^{8}$ J. RUIZ DE ARBULO y R. MAR, Op. cit.

${ }^{9}$ Sobre la figura de Joan Serra i Vilaró: M. ALMAGRO BASCH, Personalidad y obra de Juan Serra y Vilaró, Cardona, 1956; P. PALOL i SALELLAS, "Mn. Serra i Vilaró, excavador de la necrópolis cristiana de Tarragona", Boletín Arqueológico de Tarragona, época IV, $\mathrm{n}^{\underline{0}}$ 113-120, 1971-1972, pp. 11-14; A. SOBERANAS i LLEÓ, "Mossèn Joan Serra i Vilaró", Boletín Arqueológico de Tarragona, época IV, no 113-120, 1971-1972, pp. 3-9 y sobre sus excavaciones: J. SERRA I VILARÓ, Excavaciones en Tarragona, Madrid, 1932.

10 "Joan Serra i Vilaró i la Necròpolis Paleocristiana", en MNAT. Museu Nacional Arqueòlogic de Tarragona, consultado el 28 de marzo de 2014. URL: http://www. mnat.cat/?page=necropolis-visita\# .

${ }^{11}$ C. SALOM i GARRETA, Op.cit., pp. 73-75.

12 "Reales órdenes declarando Monumentos nacionales el Arco de Bará y la Torre de los Scipiones, sitos en las afueras de la ciudad de Tarragona, y el llamado Pretorio de Augusto o Castillo de Pilatos, sito en la misma ciudad", Gaceta de Madrid, no 211 de 30/07/1926, pp. 723-725. 
como monumentos histórico-artísticos la necrópolis paleocristiana, las ruinas romanas de la plaza del Pallol, el mausoleo de Centcelles y la cantera del Médoli3 ${ }^{13}$.

El desarrollo del turismo en Tarragona se apoyó en el ascenso de la clase burguesa y en la creación de lo que se ha definido como el "imaginario turístico catalán", vinculado a los movimientos excursionistas y a la Renaixença $^{14}$. La Asociación Catalanista de Excursiones Científicas, después Centro Excursionista de Cataluña ${ }^{15}$, instauró la idea del desplazamiento por ocio, fundamental en la génesis de la actividad turística ${ }^{16}$, y la aparición de las infraestructuras ferroviarias, cuya expansión tuvo lugar entre 1855 y 1856, impulsó el descubrimiento de nuevos destinos en Cataluña ${ }^{17}$. A principios del siglo $X X$, se inició la etapa de consolidación de la actividad turística en tierras catalanas y el potencial de los testimonios romanos de Tarragona comenzó a ser valorado y dio lugar a empresas interesantes, como la fundación del Sindicato de Iniciativas y Turismo (1910), cuyo objetivo era promover y difundir el legado romano y medieval del territorio ${ }^{18}$. También asistimos a

13 "Decreto de 3 de junio de 1931, declarando monumentos Históricos-Artísticos, pertenecientes al Tesoro Artístico Nacional, los que se indican", Gaceta de Madrid, no 155 , de 04/06/1931, pp. 1181-1185.

${ }^{14}$ L. A. GARAY TAMAJÓN y G. CÀNOVES VALIENTE, "Un análisis del desarrollo turístico en Cataluña a través del ciclo de evolución del destino turístico", Boletín de la Asociación de Geógrafos Españoles, vol. 52, 2010, pp. 43-58.

${ }^{15}$ J. J. MOLINA VILLAR, “La memoria del tiempo. Los orígenes de la publicidad turística en Cataluña", Estudios de Turismo de Cataluña, $\mathrm{n}^{\circ}$ 9, consultado el 12 de febrero de 2014, URL: http://fama2.us.es:8080/turismo/turismonet1/economia\%20del\%20turismo/marketing $\% 20$ turistico/origenes $\% 20 \mathrm{de} \% 201 \mathrm{a} \% 20$ publicidad $\% 20$ turistica $\% 20$ en $\% 20$ Catalunya.pdf

${ }^{16}$ S. JIMÉNEZ y Ll. PRATS, "El turismo en Cataluña. Evolución histórica y retos de futuro", Pasos. Revista de Turismo y Patrimonio Cultural, vol. 4, 2006, pp. 153.174.

${ }^{17}$ L. A. GARAY TAMAJÓN y G. CÀNOVES VALIENTE, Op.cit., pp. 48-49.

${ }^{18}$ E de ORTUETA HILBERATH, "Tarragona destino turístico. El patrimonio cultural y los nuevos espacios la adecuación del entorno de la torre de los Escipiones mediante un espacio ajardinado creado en 1929 y a la inauguración en 1933 del Paseo Arqueológico, diseñado por Jeroni Martorell también en $1929^{19}$. Ese mismo año, la Tarragona romana estuvo presente en la Exposición Universal celebrada en Barcelo$\mathrm{na}^{20}$. Algunas de sus piezas se integraron en la muestra El Arte en España (Arqueología y Bellas Artes) y las guías y publicaciones instaron a visitar la ciudad. Asimismo, también en 1929, el Patronato Nacional de Turismo promocionó los monumentos romanos de Tarragona con carteles en inglés y francés (Fig.2).

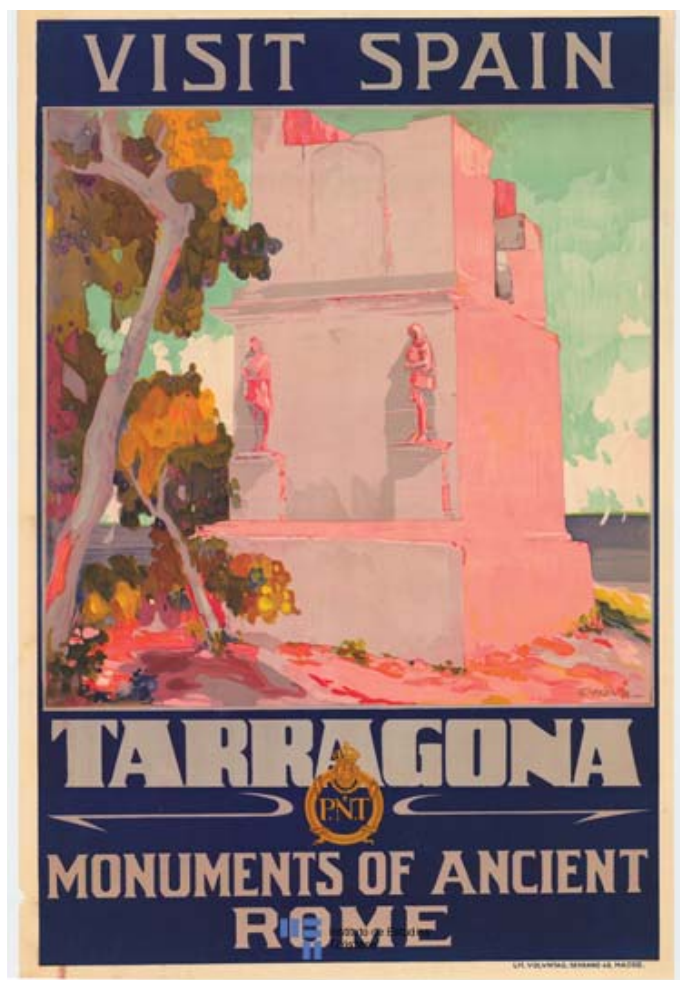

para el ócio", Norba-Arte, vol. XXVII, 2007, p.263-284.

${ }^{19}$ Ibidem, p. 268; ÍDEM, "El urbanismo en relación a los monumentos arqueológicos e histórico artísticos" en: AA.VV. Ciudades históricas vivas. Ciudades del pasado. Pervivencia y desarrollo, Mérida, 1997, pp.286-298. ÍDEM, De l'erudit al Turista. Inici de la projecció del patrimoni artístic $i$ cultural a Tarragona (1836-1923), Tarragona, 2004, pp. 155159 e ÍDEM, “La Exposición Internacional de Barcelona y su impacto en Tarragona", Anuario del Departamento de Historia y Teoría del Arte, vol. 23, 2011, pp. 183-200.

${ }^{20}$ E. DE ORTUETA HILBERATH. “La Exposición Internacional de Barcelona y su impacto en Tarragona...", pp. 183-200. 


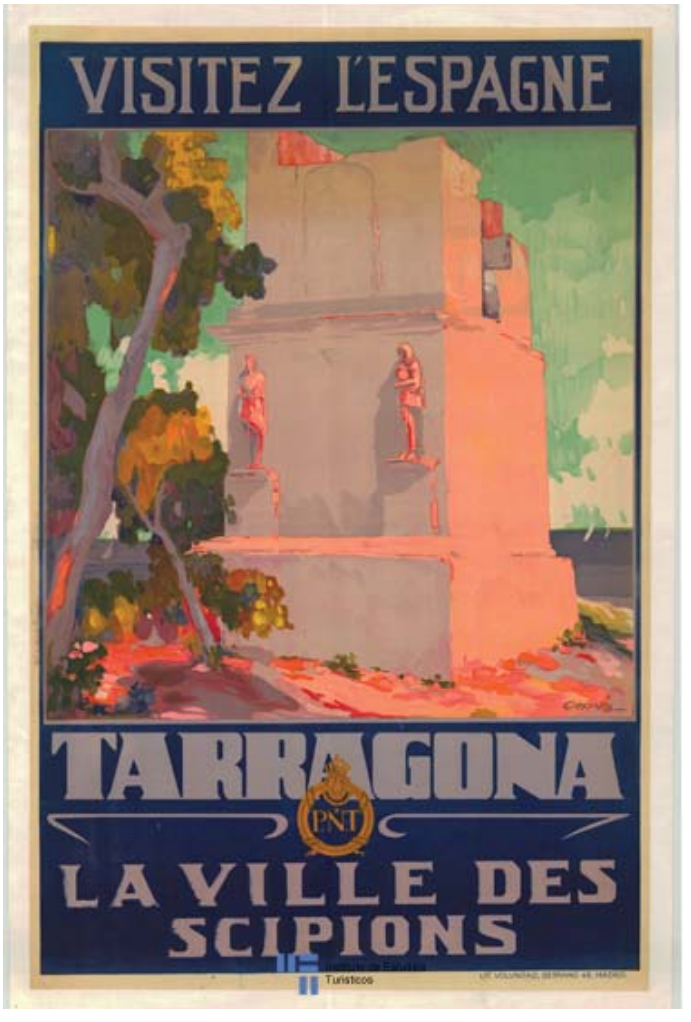

- Fig. 2 A y B. Carteles del Patronato Nacional de Turismo, 1929. Promoción internacional de los monumentos romanos de Tarragona. Instituto de Estudios Turísticos, signaturas CDTE 29-16 R.836 y CDTE 45-06 R.818.

La posguerra y el franquismo fueron testigos de nuevos descubrimientos, como los publicados por Serra i Vilaró sobre la mura$1 a^{21}$. Serra había iniciado sus investigaciones en 1932, las interrumpió para trasladarse a Italia al comienzo de la guerra civil y las reinició a su regreso en $1939^{22}$. Al acometerse la construcción del edificio del Museo Arqueológico de Tarragona en 1948, Serra fue encargado de supervisar las operaciones, al tratarse de una zona de interés arqueológico y cuando descubrió los restos de la muralla romana, comunicó el hallazgo a la Comisión de Patrimonio y lo hizo público en una entrevis-

${ }^{21}$ J. SERRA i VILARÓ, “La muralla de Tarragona”, Archivo Español de Arqueología, t. 22, no 76, 1949, pp. 221-236.

22 J. MASSÓ CARBALLIDO, “Joan Serra i Vilaró y l'exploració de la muralla romana l'any 1949. Uns quants documents inèdits", Quaderns d'Historia Tarraconense, vol. XIII, 1994, pp. 97-104. ta aparecida en el Diario Español. José Sánchez Real también llevó a cabo excavaciones en las murallas y el anfiteatro, trabajos continuados en los años cincuenta bajo la dirección de Salvador Ventura en el anfiteatro. Estas últimas intervenciones fueron costeadas por William J. Bryant y desde 1953 por un colectivo ciudadano constituido como la Asociación de Amigos del Anfiteatro ${ }^{23}$. En 1954, fue declarado monumento nacional el foro romano y en 1963 también fueron declaradas las bóvedas del $\operatorname{circo}^{24}$, atendiendo al valor de los quinientos metros lineales de las mismas que se conservaban, todo ello en un contexto ideológico en el que los testimonios del pasado romano de Tarragona cobraron un nuevo sentido.

EL IDEAL IMPERIAL RECUPERADO. PATRIMONIO, PROPAGANDA Y TURISMO EN EL PERÍODO FRANQUISTA

El simbolismo del pasado romano de Tarragona fue redefinido bajo el franquismo. Aunque el nuevo régimen puso especial énfasis en determinados momentos del pasado español, como la Reconquista, identificada con la cruzada franquista y la Edad Moderna, reflejo del ideal imperial, la prehistoria y la arqueología permitían también elaborar conclusiones sobre el origen de los españoles y su unidad como pueblo ${ }^{25}$. El pasado romano fue interpretado como el momento de la primera unificación de España y de los españoles y en el mundo romano se encontró el origen del imperio o la idea del mismo y la configuración de España como baluarte de la esencia cultural -grecorromana- y espiritual -cristiana- de

${ }^{23}$ J. RUIZ DE ARBULO y R. MAR, Op. cit.

24 “Decreto 1299/1963, de 16 de mayo, por el que se declara monumento histórico-artístico las bóvedas del circulo romano de Tarragona", Boletín Oficial del Estado, no 131 de 01/06/1963, p. 8.964.

${ }^{25}$ J.F. M. CORBÍ, “El franquismo en la arqueología: el pasado prehistórico y antiguo para la España una, grande, libre", Arqueoweb. Revista de Arqueología en Internet, no 11, 2009, consultado el 2 de marzo de 2013, URL: http://pendientedemigracion.ucm.es/info/arqueoweb/ pdf/11/corbi.pdf . 
la civilización europea ${ }^{26}$. La figura de Augusto se convirtió en el referente de jefe militar que habría terminado con la corrupción y el caos que habían dominado la fase final de la República romana y de inmediato se propuso un paralelismo entre Augusto y el caudillo Franco, con alusiones al dictador como "nuestro Imperator", "princeps, pater patriae". Asimismo, se insistió en la aportación española a la regeneración del Imperio Romano, con especial mención del emperador Trajano, o de personajes como Séneca, Marcial o Lucano, llegando a proponerse la idea de una auténtica hispanización del Imperio, y se reiteró la decisiva contribución del pueblo español a la difusión del cristianismo ${ }^{27}$.

En definitiva, la historiografía franquista desarrolló en torno al imperio romano su hito ideológico fundamental: el mito nacional español basado en la idea de la existencia de una personalidad propia española, individual y colectiva, desde el comienzo de la historia ${ }^{28}$. A partir de esta teoría identitaria se articularon la idea de la Hispanidad y la vocación imperial de España, depositaria de una "misión histórica" 29 y la noción de estado universal, de imperio o imperialismo civilizador $^{30}$. La misma concepción cimentó la ideología del estado fascista italiano, consolidado en torno a la nueva Italia liderada por Mussolini, presentado como en nuevo Augusto y con el clasicismo como uno de sus argumentos fundamentales ${ }^{31}$. En este contexto, los restos de la Tarragona romana cobraron

${ }^{26}$ Ibidem, p. 36.

${ }^{27}$ F. PINA POLO, “El estudio de la Historia Antigua de España bajo el franquismo", Anales de Historia Antigua, Medieval y Moderna, vol. 41, 2009, pp. 1-9.

${ }^{28}$ A. DUPLÁ ANSUÁTEGUI, "El franquismo y el mundo antiguo. Una revisión historiográfica", en C. FORCADELL e I. PEIRÓ (coords.), Lecturas de la Historia. Nueve reflexiones sobre la historia de la historiografía, Zaragoza, 2001, pp. 167-190.

${ }^{29}$ Ibidem, p. 175.

${ }^{30}$ Ibídem.

${ }^{31}$ A. DUPLÁ ANSUÁTEGUI, “Clasicismo y fascismo: líneas de interpretación”, en M. C. ÁLVAREZ MORÁN y R. M. IGLESIAS MONTIEL (eds.), Contempora- valor para el primer franquismo. Según Duplá, la insistencia en el concepto imperial y los paralelismos con el imperio romano constituyen una aportación propia de la ideología falangista ${ }^{32}$, cuyos intelectuales mantuvieron una especial relación con la Italia de Mussolini y tuvieron un fuerte peso en las celebraciones españolas del Bimilenario de Augusto, que supuso la utilización política del mundo antiguo ${ }^{33}$. Los actos españoles reflejaron modestamente los celebrados en Italia y giraron en torno al regalo de sendas copias del Augusto de Prima Porta a las dos ciudades españolas fundadas por el emperador ${ }^{34}$.

En la conmemoración del Bimilenario, los testimonios romanos de Tarragona tuvieron un papel destacado, si bien ese protagonismo parte de hechos anteriores a la guerra civil. En 1934, el estado italiano regaló una réplica de la escultura del Augusto de Prima Porta para que fuera instalada en el Paseo Arqueológico. La idea había partido del embajador italiano, Guariglia, quien había hecho una visita a Tarragona en enero de ese año, causándole una honda impresión sus ruinas romanas ${ }^{35}$. Según el embajador, existía en la ciudad un comité que aspiraba a colocar una efigie del emperador Augusto al pie de la muralla romana y Guariglia entendía como un gesto de propaganda italiana y de romanidad que fuera el estado italiano el que donase la estatua a los "desmemoriados y siempre degenerados sobrinos" ${ }^{\prime 36}$. Además, el diplomático consideraba garantizado el éxito de esa empresa por el apoyo del arzobispo de Tarragona, y cardenal, Francesc Vidal i Barraquer.

neidad de los clásicos en el umbral del tercer milenio, Murcia, 1999, pp. 351-359.

${ }^{32}$ Ibidem, pp. 353-354.

${ }^{33}$ A. DUPLÁ ANSUÁTEGUI, “El franquismo y el mundo antiguo...", pp. 179 y 186.

${ }^{34}$ A. DUPLÁ ANSUÁTEGUI, Ibídem, p. 186.

35 A. GONZÀLEZ i VILALTA, Cataluña bajo vigilancia. El consulado italiano y el fascio de Barcelona (19301943), Valencia, 2009, p. 147.

${ }^{36}$ Ibídem, p. 147. 


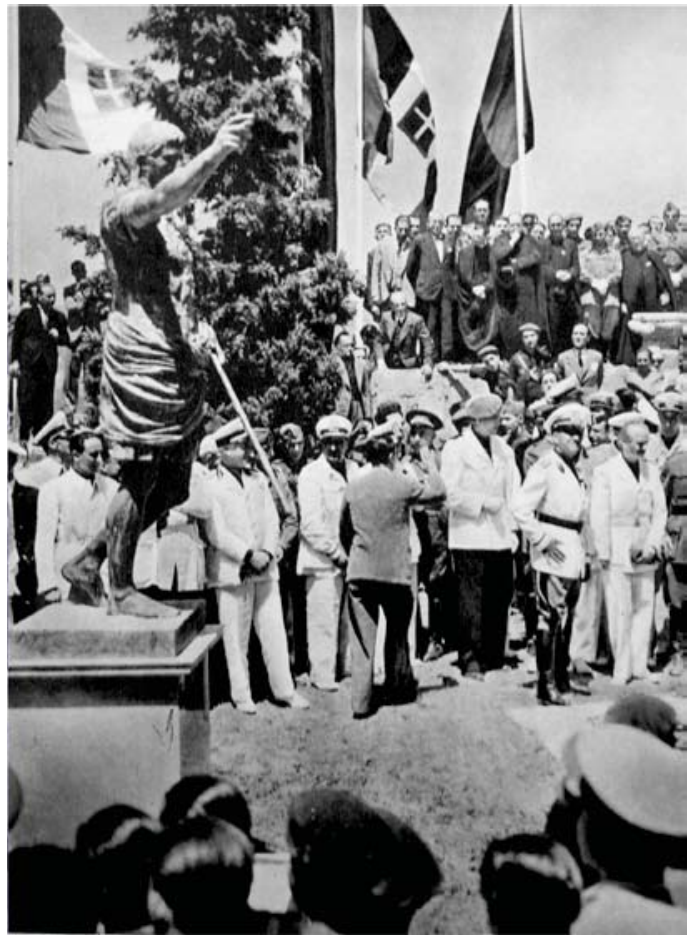

- Fig. 3 Inauguración de la estatua de Augusto en el Paseo Arqueológico de Tarragona en 1939. In nome del Duce-Galeazzo Ciano nella Spagna vittoriosa, Roma, 1939.

En 1939, el ministro de la Gobernación, Ramón Serrano Suñer ${ }^{37}$, hizo un viaje a Italia, que pronto fue devuelto por su Ministro de Asuntos Exteriores, el Conde Galeazzo Ciano, quien desarrolló una intensa actividad de marcado sesgo propagandísti$\mathrm{CO}^{38}$. La visita permitió reponer la efigie de Augusto en el Paseo Arqueológico de Tarragona, cuya inauguración el 11 de julio de 1939 sirvió de pretexto para un acto de exaltación del nuevo régimen y de su aliado italiano $^{39}$, con la asistencia del Conde Ciano ${ }^{40}$,

${ }^{37}$ P. PRESTON, "Ramón Serrano Suñer", en A. VINAS (ed.), En el combate por la historia: la República, la guerra civil, el franquismo, Barcelona, 2012, pp. 887-902.

${ }^{38} \mathrm{M}$. VÁZQUEZ ASTORGA, “Celebraciones de masas con significado político: los ceremoniales proyectados desde el Departamento de Plástica en los años de la guerra civil española", Artigrama, no 19, 2004, pp. 197226.

${ }^{39}$ F. PINA POLO, Op.cit., p. 5.

${ }^{40}$ Tárraco em la fotografia del segle XX: 1938-1979, Exposición celebrada en el Museo Arqueológico de Tarra- acompañado por Serrano Suñer (Fig.3). La comitiva triunfal recorrió la ciudad engalanada con arcos efímeros, que aparecieron en las otras ciudades recorridas por el Conde ${ }^{41}$, en los que se repetía las palabras Franco, Franco, Franco y Duce, Duce, Duce y era recibida por el público con el saludo fascista ${ }^{42}$. La prensa del momento se hizo eco de ello: "En Tarragona, el Conde Ciano y Serrano Suñer evocan la hermandad milenaria de los dos Imperios mediterráneos". También se aludía a la identificación con el régimen italiano: “Duce, fundador del nuevo Imperio de Roma, y a Franco, nuestro Caudillo, fundador, también, del nuevo Imperio español. Romanidad e hispanidad ensambladas, sin cuya Clave será imposible que la paz de la Europa asomada al mar, también fundador, tenga base perdurable"; "qué son en definitiva, "Duce" y Caudillo, sino los restauradores del arco románico con clave de hermandad entre Italia y España, perenne monumento de nuestra grandeza ante la inmortalidad de la historia" y el mismo Conde Ciano habría justificado la relación entre los dos regímenes por un "un fenómeno biológico por la afinidad de la naturaleza, del temperamento y de la mente" ${ }^{43}$. No faltaba la identificación de los restos romanos de Tarragona con los nuevos ideales imperiales: "se nos pareció más ciclópea que nunca, más augusta y más evocadora esta ciudad cargada de Historia, bajo el signo de grandezas imperiales, que ayer revivieron en un clima singularmen-

gona, consultado el 17 de febrero de 2013, URL: http:// www.mnat.cat/exposic/primv02/cat/01.htm

${ }^{41}$ M. VÁZQUEZ ASTORGA, Op.cit., pp. 213-215.

${ }^{42} \mathrm{El}$ acto es recogido por un informativo italiano. Vid. Imatges de la visita del ministre d'Afers Exteriors d'Itàlia, el comte Galeazzo Ciano, a Tarragona, el dia 11 de juliol de 1939, Museo de Historia de Tarragona, consultado el 2 de abril de 2014, URL: http://www. tarragona.cat/patrimoni/museu-historia/noticies/ imatges-del-dia-11.07.1939-reinauguracio-de-lestatua-daugust .

${ }^{43}$ Diario La Vanguardia Española, edición del miércoles 12 de julio de 1931, p. 1, consultado el 30 de octubre de 2013, URL: http://hemeroteca.lavanguardia.com/preview/1939/07/12/pagina-1/33118207/pdf.html . 
te apto para la remenbranza" ${ }^{44}$ y no menos contundente se mostraba el Diario $A B C$ en su editorial: "Ante el mar Mediterráneo, que surcan libres, altivas y victoriosas las naves de Italia y España, sellan los ministros Conde Ciano y Serrano Suñer la amistad de las dos potencias imperiales" ${ }^{45}$. Serrano Suñer aludió asimismo al pasado romano de Tarragona: “... Y esas piedras, las columnas y los arcos romanos que en toda la ciudad encontraréis, son un testimonio del cariño y del amor con que guardan los tarraconenses los gloriosos vestigios" ${ }^{\prime 46}$ y las interpretó desde un punto de vista ideológico, afirmando que era lógico que Benito Mussolini dedicase en Tarragona la efigie de Augusto para que fuera "honrada en perpetua memoria por los españoles", para terminar con los gritos de "Roma Eterna" y "España Excelsa" y vítores a España, al Duce y a Franco ${ }^{47}$. Por su parte, el Conde Ciano afirmaba que en Tarragona "todo habla de romanidad".

La visita del conde Ciano también permitió dotar de connotaciones simbólicas fascistas al arco de Bará. El 11 de julio de 1939, se llevó a cabo un acto de homenaje a los soldados italianos caídos en la guerra civil española y se instaló en sus inmediaciones un ara con los emblemas del fascio y la inscripción "Commilitonibus legionariis in Hispania decessis praesentes", que fue posteriormente demolida en $1949^{48}$.

Otro acto en esta misma línea de identificación ideológica, tuvo lugar en el Paseo Arqueológico a principios de los años cincuenta, cuando el alcalde de Tarragona y el Delegado de la Dirección General de

${ }^{44}$ Ibídem, p. 1.

${ }^{45}$ Diario $A B C$, edición del 12 de julio de 1939, consultado el 30 de octubre de 2013, p. 9, URL: http://hemeroteca.abc.es/nav/Navigate.exe/hemeroteca/madrid/ abc/1939/07/12/009.html .

${ }^{46} \mathrm{Ibídem,} \mathrm{p.} 10$.

${ }^{47}$ Ibídem.

${ }^{48}$ X. DUPRÉ i RAVENTÓS, L'Arc Romà de Berà, Sabadell, 1994, p. 136 y diario La Vanguardia Española, edición del miércoles 12 de julio de $1931 \ldots$, p. 1.
Turismo plantaron en el mismo un laurel procedente del foro de Roma ${ }^{49}$. Y no menos significativo es el hecho de la visita al Paseo de turistas alemanes en 1940, acompañados del alcalde de la ciudad y el Jefe Provincial de Falange, tal y como refleja una fotografía de Victor Horn, fotógrafo de ideología nazi afincado en Cataluña ${ }^{50}$.

Durante el período franquista, por tanto, los testimonios del pasado romano merecieron una especial consideración y fueron objeto de intervenciones encaminadas a su puesta en valor ${ }^{51}$, como la creación de la nueva sede del Museo Arqueológico, a iniciativa de su exdirector, Joaquín María de Navascués, que propuso construir un edificio independiente y dedicado de forma monográfica a exponer y tutelar los fondos arqueológicos que se habían ido recuperando en Tarragona desde mediados del siglo XIX. En 1940, Francesc Monravà i Soler elaboró un anteproyecto, que cristalizó tres años después y que tardó en materializarse por las dificultades derivadas del descubrimiento de los restos de la muralla romana en el solar que debía ocupar el Museo. Las obras se desarrollaron entre 1948 y 1960 y la instalación museística fue supervisada por Manuel Jorge Aragoneses, Director de la Comisaría Nacional. La ceremonia de inauguración tuvo lugar el 12 de mayo de 1960 y contó con la presencia de las máximas autoridades ministeriales y del obispo tarraconense $\mathrm{e}^{52}$. Asimismo, Francisco Franco visitó las excavaciones del anfiteatro en 1952, acompañado de su esposa ${ }^{53}$ y no debemos olvidar los en-

${ }^{49}$ La escena aparece en una imagen de la exposición: Tárraco em la fotografia del segle XX...

${ }^{50}$ La imagen aparece en Ibídem. Sobre Victor Horn: FUNDACIÓ CAIXA TARRAGONA, Amb un altre objectiu. Victor Horn un fotògraf Alemany a la guerra civil, Tarragona, 2000.

${ }^{51}$ E. de ORTUETA HILBERATH, “Tarragona destino turístico...", p. 282.

${ }^{52}$ La escena aparece en una imagen de la exposición: Tárraco em la fotografia del segle XX...

${ }^{53} \mathrm{El}$ acto queda reflejado en dos fotografías de Ibídem. 
cuentros científicos celebrados en Tarragona y los cursos internacionales de arqueología y prehistoria que dotaban de proyección a la Tarraco romana. Con la llegada del desarrollismo, aumentó el valor de los testimonios romanos tanto para el turismo internacional $^{54}$, como para el nacional. A los veraneantes de la Ciudad Residencial tarraconense se les ofrecían visitas a las ruinas romanas y el arco de Bará ${ }^{55}$ y en los años sesenta la ciudad contaba con un hotel destinado a alojar a las clases acomodadas, cuyo nombre no puede ser más significativo: Imperial Tarraco.

En este contexto de aprecio y utilización ideológica y económica de los restos de época romana, tuvo lugar la declaración de la ciudad como Conjunto Histórico-Artísti$\mathrm{Co}^{56}$. En el decreto correspondiente se hace alusión a que Tarraco fue uno de los centros fundamentales de introducción del cristianismo y estuvo estrechamente relacionada con la venida de San Pablo a España y también a su destrucción durante la dominación islámica, identificando al enemigo de la Reconquista como destructor, de la misma forma en que se había identificado a los enemigos del franquismo con las destrucciones del patrimonio español. El conjunto monumental integró elementos que ya contaban con declaración monumental: la catedral, el acueducto, el anfiteatro, las bóvedas del circo, las murallas, la necrópolis romanocristiana, el pretorio o palacio de Augusto, el foro, las ruinas de la plaza de Pallol, la iglesia de Santa María del Miracle y la torre de los Escipiones. Asimismo, se incluyeron las "calles tortuosas y estrechas conforme a la tipografía urbana medieval en las que existen casas muy representativas que conservan elementos sumamente característicos y res-

\footnotetext{
${ }^{54}$ Sobre este contexto: S. PACK, La invasión pacífica: los turistas y la España de Franco, Madrid, 2009.

${ }^{55}$ E. de ORTUETA HILBERATH, “Tarragona destino turístico...", p. 277.

56 “Decreto 652/1966, de 10 de marzo, por el que se declara Conjunto Histórico-Artístico la ciudad de Tarragona", Boletín Oficial del Estado, no 69 de 22/03/1966, p. 3.411 .
}

tos arquitectónicos del más alto interés". Se establecieron las zonas de protección de la siguiente manera: la zona histórico-artística propiamente dicha, que debía conservarse "en todo su carácter y ambiente"; la zona de respeto, en la que debían controlarse los hallazgos arqueológicos de acuerdo a las leyes vigentes y también la altura y el volumen de las edificaciones, con el fin de salvaguardar la silueta urbana y la vista exterior de la ciudad; finalmente, en el resto de la ciudad y sus zonas de extensión, "sin imponerse normas de volumen ni estilo de las edificaciones", se recordaba la obligatoriedad de cumplir rigurosamente la legislación en materia arqueológica $^{57}$.

Esta declaración se hizo desoyendo una primera propuesta del ayuntamiento tarraconense que sugería distinguir tres zonas: la histórico-artística propiamente dicha, Correspondiente con el sector de las murallas; la zona de respeto, en términos idénticos a los expuestos en la declaración, y finalmente una zona de ordenación especial que debía comprender el anfiteatro, el foro romano y la necrópolis y que suponía una tutela más amplia de la compleja historia urbana de la ciudad. Parece que el Ministerio de Educación Nacional integró parte de los criterios de José María de Navascués y priorizó la protección de los restos romanos frente a la del casco histórico, o parte alta de la ciudad, al considerar que su trazado era dudosamente típico por haber quedado sometido al aprovechamiento de las ruinas romanas desde la Edad Media, y sobrevaloró los yacimientos arqueológicos de toda la ciudad ${ }^{58}$. Esta falta de aprecio del urbanismo de la Tarragona medieval, parece haber sido una constante que detectamos en los escritos de los viajeros de la época moderna y la declaración supuso una imposición del valor del pasado romano sobre las restantes etapas históricas de la ciudad, que ha determinado todas las políticas de tutela posteriores y la

\footnotetext{
${ }^{57}$ Ibídem, noํ 2 de 03/01/1978, p. 96.

${ }^{58}$ E. de ORTUETA HILBERATH, “Tarragona destino turístico...", pp. 281-282.
} 
inclusión en la Lista del Patrimonio Mundial del Conjunto Arqueológico de Tárraco en el año 2000. Además, la declaración interpretaba el conjunto urbano como una suma de monumentos, yacimientos y edificios de interés, pero no abordaba su interrelación. Podemos entender así su alusión a los restos de la etapa medieval, insertos en una trama urbana tortuosa, pero haciendo hincapié en aquellas casas que conservasen elementos característicos o restos de interés. Esta concepción refleja la tónica de las intervenciones en los centros históricos en el período franquista, marcadas por la recreación, la monumentalización y la elaboración de itinerarios o recorridos para cuya creación no se dudó en trasladar fachadas o elementos de interés o en repristinar determinados edificios ${ }^{59}$.

La actividad arqueológica en Tarragona entre 1939 y 1979 estuvo limitada por las condiciones económicas generales y locales. Alguna investigación fue sostenida por iniciativas de fundaciones y entidades científicas extranjeras, como sucedió con las ya citadas intervenciones en el anfiteatro, subvencionadas por la Fundación Bryant o con la recuperación del mausoleo de Centcelles y las exploraciones en la muralla, tuteladas por el Instituto Arqueológico Alemán, y no existieron excavaciones de cierta extensión, una inercia que comenzó a romperse con las efectuadas en la plaza del Foro o del Teatro.

${ }^{59}$ M. A. PARDO FERNÁNDEZ, “El arquitecto José Menéndez-Pidal y sus criterios de restauración monumental sobre los conjuntos históricos artísticos", Laboratorio de Arte: Revista del Departamento de Historia del Arte, no 25, 2, 2013, pp. 811-827; ÍDEM, “La "ambientación" de la ciudad histórica. Restauración monumental y urbana en los años sesenta", en M. A. ZALAMA RODRÍGUEZ y P. MOGOLLÓN CANO-CORTES, Alma ars: estudios de arte e historia en homenaje al Dr. Salvador Andrés Ordax, Valladolid, 2013, pp. 341-346 y B. CASTRO FERNÁNDEZ y A. HERNÁNDEZ MARTÍNEZ, “Patrimonio monumental y turismo. La ordenación de conjuntos monumentales en Aragón: el caso de Sos del rey Católico (Zaragoza)", e-rph (en línea), no 13, diciembre de 2013, consultado el 7 de enero de 2014, URL: http:// www.revistadepatrimonio.es/revistas/numero13/intervencion/estudios2/articulo.php .
Mención aparte merecen las restauraciones del pretorio o del foro romano ${ }^{60}$.

Finalmente, la declaración de Conjunto Histórico-Artístico de Tarragona no fue todo lo efectiva que cabía esperar. Las excavaciones preceptivas en las zonas delimitadas quedaron a cargo del Museo Arqueológico Provincial y por iniciativa de su director se llevaron a cabo entre 1967 y 1970 investigaciones en el foro, la plaza de la Audiencia y el teatro romano. Pero las limitaciones del Museo, la falta de amparo legal y de apoyo de las instituciones y los intereses de los constructores, redujeron las posibilidades reales de tutelar los restos hallados ${ }^{61}$. Cuando en 1970-73 las instalaciones fabriles emplazadas sobre los restos del teatro fueron abandonadas, los terrenos fueron declarados edificables, pese a la oposición de diferentes instituciones, y cuando se desalojaron las fábricas en 1974, fueron vendidos como solares. Los permisos de construcción correspondientes estaban condicionados por el resultado de las excavaciones emprendidas por el Museo Arqueológico, pero pese a sus importantísimos descubrimientos, no se suspendieron las obras y fueron los colectivos ciudadanos los que finalmente consiguieron paralizarlas, aunque la solución definitiva iba a tardar en llegar $^{62}$. En 1978 se procedió a la incoación del expediente de declaración monumental, que nunca llegó a materializarse y fue archivada en 2013, para proceder a incoarse la declaración de Bien de Interés Cultural de Interés Nacional, al amparo de la ley 9/1993, de 30 de septiembre, del Patrimonio Cultural Catalán ${ }^{63}$. Finalmente, el teatro fue incluido en

60 "L'arqueologia, la transformació de la ciutat i les noves investigacions arqueològiques", en Tárraco em la fotografia del segle XX...

${ }^{61}$ J. RUIZ DE ARBULO y R. MAR, Op. cit.

${ }^{62}$ R. MAR, M. ROCA y J. RUIZ DE ARBULO, "El Teatro Romano de Tarragona. Un problema pendiente", Teatros Romanos de Hispania. Cuadernos de Arquitectura Romana, vol. II, 1993, pp. 11-23.

63 “Resolución CLT/1691/2013, de 17 de julio, por la que se archiva el expediente de declaración de monu- 
la Declaración de Patrimonio Mundial del Conjunto Arqueológico de Tárraco en el año $2000^{64}$

LAS INTERVENCIONES DE ALEJANDRO FERRANT EN LOS TESTIMONIOS DE LA TARRAGONA ROMANA.

Alejandro Ferrant Vázquez (Madrid 1897-1976) se formó como arquitecto restaurador junto a Manuel Gómez-Moreno ${ }^{65}$ y se integró en el primer grupo de arquitectos de zona en 1929, para hacerse cargo de la primera. Tras la guerra civil y un apartamiento temporal de la labor restauradora, fue destinado a la cuarta zona, que comprendía Cataluña, la actual Comunidad Valenciana y las Islas Baleares. Desarrolló una intensa labor hasta el final de su vida y mantuvo las bases de su formación en los principios de la restauración científica, pero integró también recursos propios de la restauración recreadora $^{66}$. Como arquitecto de la cuar-

mento histórico-artístico y arqueológico del teatro romano y su entorno en Tarragona, y se incoa expediente de declaración de bien cultural de interés nacional, en la categoría de monumento histórico, a favor del teatro romano y de las termas públicas de Tarragona, y en la categoría de zona arqueológica, a favor del teatro romano, las termas públicas y el área monumental anexa de Tarragona", Boletín Oficial del Estado, no 228 de 23/09/2013, sección III, p. 76928.

${ }^{64}$ Los criterios que justifican la declaración son el II y el III y los bienes incluidos son los siguientes: murallas romanas, recinto de culto imperial, Foro Provincial, Foro Colonial, circo, teatro romano, anfiteatro y basílica e iglesia románica del Milagro, necrópolis paleocristiana, acueducto, torre de los Escipiones, cantera del Médol, villa y mausoleo de Centcelles, villa dels Munts y Arco de Bará. Archaeological Ensemble of Tárraco, consultado el 27 de febrero de 2014. URL: http://whc.unesco. org/en/list/875 .

${ }^{65}$ M. P. GARCÍA CUETOS, "Alejandro Ferrant y Manuel Gómez-Moreno: aplicación del método científico del CEH a la restauración monumental", Logia. Arquitectura \& Restauración, ํo 21, 2008, pp. 8-25.

${ }^{66}$ Sobre la figura de Alejandro Ferrant: J. ESTEBAN CHAPAPRÍA y M. P. GARCÍA CUETOS Alejandro Ferrant y la conservación monumental en España. Castilla León y la Primera zona Monumental, Valladolid, 2007; M. P. GARCÍA CUETOS, “La labor de Alejandro Ferrant Vázquez en Cataluña durante el primer franquismo", en M. ta zona, actuó sobre los restos romanos de Tarragona, siempre asesorado por la comisión encargada de determinar las intervenciones a realizar en los mismos, que había sido creada por el Ministerio de Educación Nacional en 1962 y que estaba formada por Alejandro Ferrant y los arqueólogos e historiadores Pere Batlle Huguet, Joaquín María de Navascués, José Samuel Ventura Solsona y Joan Serra i Vilaró. La articulación de esta comisión daba respuesta al interés que los testimonios despertaban y a la necesidad de contar con un equipo asesor especializado. Sus componentes, junto con su director, Antonio García Bellido, visitaron el anfiteatro, el pretorio y el foro en 1962, con el objeto de comprobar in situ su estado y el avance de las intervenciones ${ }^{67}$.

\section{ACTUACIONES EN LA NECRÓPO- LIS PALEOCRISTIANA}

La necrópolis se localiza junto al río Francolí en terrenos de lo que fueron los suburbios de Tarraco y sus restos se articulan siguiendo un vial romano que sigue el curso fluvial. Fue descubierta casualmente en 1923, con motivo de la construcción de una fábrica de tabacos. El Institut d'Estudis Catalans llamó la atención sobre ese hallazgo y las excavaciones arqueológicas en el lugar fueron llevadas a cabo por Joan Serra i Vilaró entre 1926 y $1933^{68}$. Se descubrió un conjunto funerario considerado como el

P. GARCÍA, E. ALMARCHA y A. HERNÁNDEZ, Restaurando la Memoria. España e Italia ante la recuperación monumental de posguerra, Gijón, 2010, pp. 67-92 y “Reconquista litúrgica y restauración. Alejandro Ferrant y las catedrales de la Cuarta Zona Monumental", en M. P. GARCÍA, E. ALMARCHA y A. HERNÁNDEZ, Historia, restauración y reconstrucción monumental en la posguerra española, Madrid, 2012, pp. 65-95.

${ }^{67}$ Diario $A B C, 18$ de febrero de 1962, consultado el 21 de febrero de 2014, URL: http://hemeroteca.abc.es/nav/ Navigate.exe/hemeroteca/madrid/abc/1962/02/18/069. html .

${ }^{68}$ J. C. SERRA i RAFOLS., "El Museu Arqueològic de la Necròpolis romana del Francolí, Tarragona", Anuari de l'Institut dé Estudis Catalans, vol. XXXI, 1927, pp. 225-226. 
más notable de todo el Occidente romano ${ }^{69}$ y su importancia ha sido ratificada por las investigaciones llevadas a cabo en los años noventa del siglo $X X^{70}$. Serra i Vilaró ${ }^{71}$ logró la conservación, musealización y puesta en valor del yacimiento y su dedicación a la necrópolis fue reconocida al ser inhumados sus restos en la misma en 1969. También alentó la construcción del Museo Arqueológico de la Necrópolis Romana ${ }^{72}$, un edificio de estilo neoclásico ecléctico, inaugurado en 1930 y cuya zona inferior acoge parte del yacimiento. Su planta principal estaba formada por una nave central rodeada de una galería, disposición que permite conservar in situ un buen número de sepulturas sin abrir o solo parcialmente excavadas. Se consideraba que, al conservarlas de esa forma y dentro del museo, las tumbas tendrían una mayor capacidad de sugestión para el visitante que no fuera arqueólogo y al mismo tiempo se mantenía la posibilidad de posteriores estudios. En el piso superior, se alojaron los hallazgos considerados más valiosos, distribuidos entre la sala central y la galería. El resto de la necrópolis, cuyas tumbas de piedra sin decoración se consideraron menos valiosas y más resistentes, se mantuvo al aire libre, en el convencimiento de que podrían soportar los efectos de la intemperie durante muchos años $^{73}$.

${ }^{69}$ J. RUIZ DE ARBULO y R. MAR, Op. cit. y "La necrópolis Paleocristiana. Descobriment i recerca", MNAT. Museu Nacional Arqueòlogic de Tarragona, consultado el 28 de marzo de 2014. URL: http://www.mnat. cat/?page $=$ necropolis-visita\# .

${ }^{70} \mathrm{~J}$. LOPEZ i VILLAR, “Un nuevo conjunto paleocristiano en las afueras de Tarraco", Revista de Arqueología, no 197, 1997, pp. 58-64.

71 "Joan Serra i Vilaró i la Necròpolis Paleocristiana", MNAT. Museu Nacional Arqueòlogic de Tarragona, consultado el 28 de marzo de 2014, URL: http://www. mnat.cat/?page $=$ necropolis-visita $\#$.

72 J. SERRA i VILARÓ, Excavaciones en la necrópolis romano-cristiana de Tarragona: memoria, "Volumen 133 de Junta Superior del Tesoro Artístico: Sección de Excavaciones", Madrid, 1935.

${ }^{73}$ J. C. SERRA i RAFOLS., Op.cit., pp. 225-226.
A principios de los años setenta, Alejandro Ferrrant encargó al arquitecto Emilio Pérez Piñero una estructura que cubriera parte de la necrópolis, puesto que los daños causados por su permanencia al aire libre se habían hecho patentes. En esos mismos años, Pérez Piñero diseño otra estructura igualmente interesante y novedosa: la cúpula reticular poliédrica del Museo Dalí de Figueres. Se trata de dos iconos de la arquitectura estructural utilizada para la musealización y la conservación del patrimonio ${ }^{74}$. Con ellas, Pérez Piñero consiguió cubrir dos espacios museológicos de forma eficiente y respetuosa, siguiendo los principios de la Carta de Venecia de $1964^{75}$. Ferrant fue informado por Carlos de Miguel, Fernando Chueca y García Fernández de que Pérez Piñero era capaz de afrontar el reto de cubrir de forma efectiva el amplio espacio de la necrópolis de Tarragona y en agosto de 1970 le envió un plano del yacimiento y de las últimas excavaciones llevadas a cabo y le informó de que contaba con un presupuesto de un millón de pesetas. Hechas las oportunas gestiones por parte de Ferrant, en su calidad de arquitecto de zona, el Ministerio de Educación y Ciencia cursó el encargo a Pérez Piñero. Su proyecto se basaba en la idea de cubrir el amplio espacio mediante dos estructuras rectangulares. La primera fase está compuesta por ocho bóvedas vaídas reticulares (Fig.4) apoyadas sobre sus cuatro vértices mediante soportes metálicos anclados con hormigón armado, dispuestos de tal manera que no afectan al yacimiento. Pérez Piñero señalaba, además, que esas estructuras recibían muy bien una cubierta de fibrocemento de "agradable efecto estético"76. En 1971, las cimentaciones de los anclajes de hormigón de la primera fase estaban dispuestas, pero la obra se re-

${ }^{74}$ C. PÉREZ ALMAGRO, "Las estructuras de Emilio Pérez Piñero en la musealización de dos espacios singulares", Midas, vol. 1, 2013, pp. 1-12, consultado el 26 de marzo de 2013, URL: http://midas.revues.org/101.

${ }^{75}$ Ibídem, p. 2.

${ }^{76}$ Ibídem, p. 9 y E. PÉREZ PIÑERO, "Cubierta en el Museo Paleocristiano de Tarragona", Arquitectura, no 163-164, 1972, pp. 20-21. 
trasó, aunque finalmente el arquitecto pudo entregarla, si bien su coste final dobló el presupuesto inicial. Con todo, los esfuerzos de Pérez Piñero se vieron recompensados por el éxito de su estructura, que fue muy valorada tanto por el Ministerio como por el $\mathrm{Mu}-$ seo de Tarragona y recibió el encargo de realizar la segunda fase de la cubierta. El fallecimiento de Emilio Pérez Piñero impidió que él fuera el encargado de este proyecto, que finalmente fue asumido por su hermano José María, bajo cuya dirección se culminó la estructura en el verano de $1973^{77}$. Esta cubierta fue renovada en los años 90, retirándose los elementos de fribrocemento, que fueron sustituidos por otros de polivinilo translúcido.

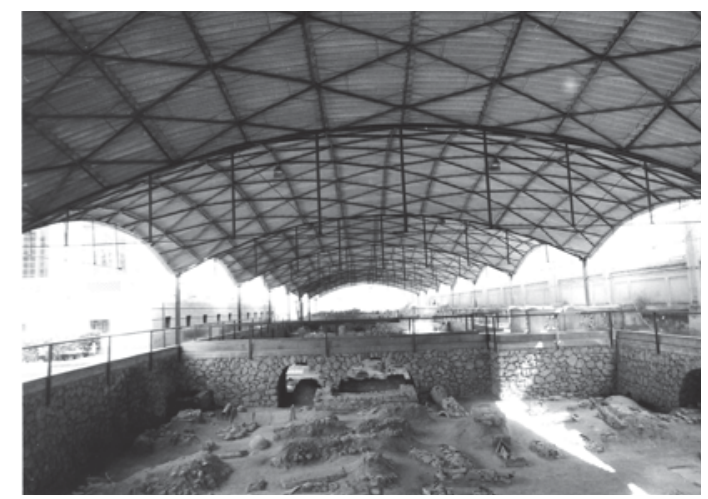

- Fig. 4 Cubierta de la Necrópolis de Tarragona. Fundación Emilio Pérez Piñero, signatura 52.

En 1992, la necrópolis fue cerrada al público y sometida a una intervención que ha pretendido devolverle "la imagen que podría haber tenido ese espacio en época romana", ponerlo en valor, asegurar su conservación y facilitar su comprensión ${ }^{78}$. Abierta al público en mayo de 2013, esta adecuación forma parte de un proyecto que tiene cono objetivo la creación del complejo de equipamiento cultural de La Tabacalera, al que está previsto trasladar el Museo Arqueológico

\footnotetext{
${ }^{77}$ C. PÉREZ ALMAGRO, Op.cit., p. 10.

78 "Reobertura de la necrópolis paleocristiana de Tarragona", Generalitat de Catalunya, Departament de Cultura, consultado el 13 de enero de 2014, URL: http://premsa.gencat.cat/pres_fsvp/ docs/2013/05/21/10/36/940b5fb5-cb2e-467e-a6a640405a164120.pdf .
}

de Tarragona, la Biblioteca Pública de Tarragona y el Depósito Arqueológico Nacional, de manera que podemos preguntarnos por el futuro del primer edificio del Museo Arqueológico tarraconense, cuyo valor arquitectónico y museográfico nos gustaría poner de manifiesto.

\section{ACTUACIONES EN EL ANFITEATRO}

El anfiteatro romano de Tarragona fue edificado en la primera mitad del siglo II fuera de la muralla y junto a la playa del Miracle, y reformado bajo el reinado del emperador Heliogábalo en el año 221. Las gradas se construyeron aprovechando la inclinación natural del terreno, si bien fue necesario igualmente construir una estructura de soporte, con los preceptivos vomitorios para facilitar el acceso y la salida del público. El edificio fue abandonado en el siglo $\mathrm{V}$ y en la centuria siguiente acogió en su interior una pequeña basílica y un cementerio. La iglesia fue abandonada en torno al siglo VIII y en el siglo XII fue erigido sobre sus restos un nuevo templo dedicado a Santa María. En 1571 se instaló en el lugar un convento de Trinitarios, que en 1801 fue dedicado a cárcel ${ }^{79}$, y en cuyas inmediaciones se edificó el Baño de Olas, según un diseño de José Revoltós i Tomas de 1882. Poco después, las labores de desmonte de las edificaciones de la antigua cárcel fueron llevadas a cabo de forma poco rigurosa y ello provocó el arruinamiento parcial de la iglesia del Miracle en $1915^{80}$.

Las primeras excavaciones arqueológicas fueron iniciadas en 1948 por Samuel Ventura, con la colaboración del arquitecto Salvador Ripoll y el apoyo económico de la Fundación Bryant ${ }^{81}$. Estas investigaciones despertaron el interés por las ruinas y en los años cincuenta se realizaban visitas escolares al anfiteatro, en las que miembros de la

\footnotetext{
${ }^{79}$ A. JORDÀ FERNÁNDEZ, Op.cit., pp. 30-32.

${ }^{80}$ E. de ORTUETA HILBERATH, “Tarragona destino turístico...", p. 270.

${ }^{81}$ S. VENTURA SOLSONA, Excavación en el Anfiteatro Romano de Tarragona, Tarragona, 1954.
} 
asociación Amics del Anfiteatre impartían explicaciones $^{82}$. En 1962, como ya sabemos, la comisión presidida por Antonio García Bellido, giró visita al anfiteatro para dictaminar sobre su proceso de reconstrucción. Ese mismo año, Alejando Ferrant proponía una primera intervención de restauración y excavación ${ }^{83}$, centrándose en la búsqueda de los frontales del graderío y otros testimonios de la construcción en el frente oeste del eje mayor del edificio. El proceso de excavación partía de un rebaje sistemático de tres metros en la zona elegida. Previamente al inicio de los trabajos, la zona fue delimitada y cerrada mediante una valla metálica, que se completaría con un seto de ciprés con el fin de "embellecer" la estructura y paliar su impacto en el conjunto.

Los trabajos de Ferrant prosiguieron en 1963 y se centraron en la consolidación de los muros de los pasillos de acceso a la cavea y los de las iglesias ${ }^{84}$. En los pasillos, se trataba de vaciar todos los elementos acumulados a lo largo del tiempo, para localizar los cimientos y establecer si era necesario recalzarlos. Ferrant tenía la esperanza de hallar el solado original y un posible desagüe de la arena del Anfiteatro, aunque en caso de no localizarlo proponía hacer uno.

La clarificación de este complejo proceso de restauración es difícil, si bien Ferrant elaboró a lo largo del tiempo diferentes planos detallando las zonas a intervenir y algunas fotografías, de manera que podemos conocer dónde llevó a cabo las restauraciones y algunos de sus pormenores. En 1964, el arquitecto daba cuenta de lo dificultoso del proceso de recuperación del desagüe roma-

${ }^{82}$ La escena aparece en una imagen de la exposición: Tárraco em la fotografia del segle XX...

${ }^{83}$ Biblioteca Valenciana Nicolau Primitiu. Archivo Alejandro Ferrant Vázquez (en adelante BVAAFV). Obras de cerramiento e inicial de excavaciones en el Anfiteatro Romano de Tarragona. Memoria. Signatura 947. 17 de julio de 1962.

${ }^{84}$ BVAAFV. Obras de conservación en el Anfiteatro de Tarragona. Memoria. Signatura 948. 31 de mayo de 1963. no, que finalmente había sido localizado ${ }^{85}$. También se descubrieron restos de la fachada al mar y se proponía un gran movimiento de tierras para sacarlos completamente a la luz, recuperando todos los elementos que la voladura llevada a cabo por las tropas francesas en 1813 había trastocado. Se contemplaba la recuperación de elementos escultóricos o arquitectónicos, la conservación de todo aquello que se hubiera mantenido en su lugar, un análisis de las capas de terreno no removido que pudieran proporcionar datos del edificio y completar algunas zonas de bóveda o muros arruinados, diferenciándolos claramente, con la intención de "lograr una mayor sensación de grandiosidad" del monumento. En 1967, Ferrant reseñaba que debido a la falta de técnicos que pudieran supervisar permanentemente las excavaciones arqueológicas, los trabajos debieron localizarse en el descubrimiento de las construcciones que constituían la entrada del anfiteatro y enlazaban con las estructuras abovedadas del sector del graderío próximo al $\operatorname{mar}^{86}$.

Aunque desde 1963 se pretendía reconstruir el podium, esta intervención no se había llevado a cabo y volvía a proponerse en 1967, señalándose que se utilizaría para ello hormigón, que puntualmente podría ser recubierto con los fragmentos de la fábrica romana que se hubieran recuperado, mientras que el resto sería aplacado con piedra que "entonase" y recordase la original. En este momento, ya se puntualizaba que el 50\% del presupuesto de las obras propuestas en el mismo debían ser costeadas por el Ayuntamiento de Tarragona. En 1968 habían aparecido los restos del acceso oeste al conjunto y se habían reconstruido las bóvedas de la zona sur, donde se abrían las entradas de la

${ }^{85}$ BVAAFV. Obras de conservación en el Anfiteatro de Tarragona. Memoria. Signatura 949. 8 de mayo de 1964.

${ }^{86}$ BVAAFV. Obras de conservación en el Anfiteatro de Tarragona. Memoria. Signatura 950. 31 de marzo de 1967. 
fachada marítima del Anfiteatro ${ }^{87}$. También se había localizado la escalinata que accedía en rampa sobre el eje mayor, flanqueada por las dependencias auxiliares. La gran cantidad de tierras acumuladas en esta zona obligó a completar las excavaciones iniciadas en 1967 en esta siguiente anualidad y los restos descubiertos fueron consolidados y restaurados, proponiéndose la reconstrucción de las fábricas de sillería y sillarejo y de un arco fajón de medio punto, cuyos arranques habían sido encontrados a unos siete metros de la puerta de acceso. En ese momento, Ferrant esperaba que los nuevos trabajos completasen los estudios desarrollados hasta el momento, permitiendo acotar la fecha de construcción del anfiteatro tarraconense.

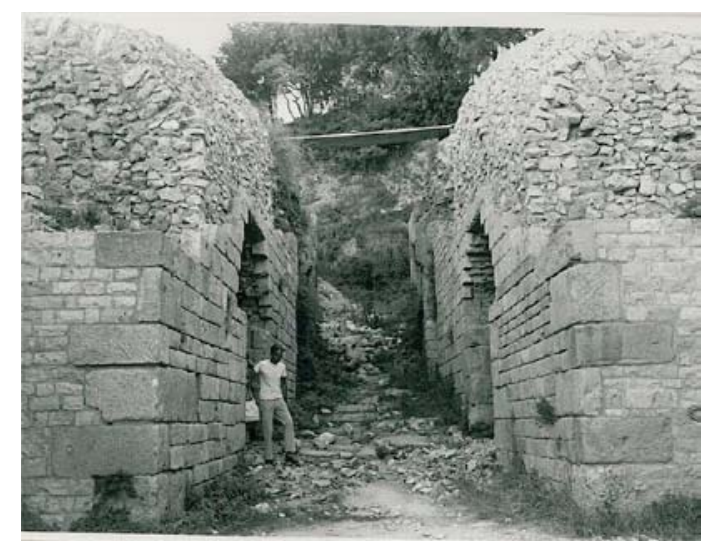

- Fig. 5 Zona de bóveda a reconstruir en el acceso al anfiteatro y que debía servir de base al tramo del graderío que se dispondría encima. Biblioteca Valenciana. Archivo Alejandro Ferrant Vázquez. Obras de conservación en el Anfiteatro Romano de Tarragona. Memoria. Signatura 955. 13 de abril de 1972.

En 1970 ya se había reconstruido en lo posible la entrada oeste del eje mayor de la elipse y el graderío inmediato en dirección al mar y se proponía rehacer los abovedamientos del tramo central en la zona superior (Fig.5) y la consolidación de las correspondientes en la zona inferior, creando de esa forma el basamento para rehacer

${ }^{87}$ BVAAFV. Obras de conservación en el Anfiteatro de Tarragona. Memoria. Signatura 951. 27 de mayo de 1968. un nuevo tramo del graderío ${ }^{88}$. Asimismo, se quería levantar "discretamente", hasta una altura que los hiciera legibles, los muros de la entrada desde la fachada marítima. En 1971 se continuó la reconstrucción del graderío y se completó la entrada del suroeste $^{89}$. Se pensaba rehacer los muros de las dependencias que la flanqueaban, para proceder posteriormente a elevar sobre ellas una bóveda de cañón, que serviría de base al graderío y a la fachada marítima en esa zona, porque ya se tenía claro que, de todas las del anfiteatro tarraconense, esa había sido la más monumental. Los muros reconstruidos se recubrirían con una fábrica de sillarejo similar a la original y también se intentaría recuperar el posible aspecto de las puertas de acceso a los departamentos que flanqueaban la entrada. En cambio, los senos de las bóvedas se macizarían con hormigón en masa, extendiendo una capa de asiento donde debían colocarse las gradas que se pensaba reconstruir y que enlazarían con la ya repuestas. En 1972, el largo proceso de recuperación del anfiteatro continuaba y se certificaba que estaban finalizadas las obras de recuperación de la entrada oeste $y$ sus edificaciones anejas ${ }^{90}$. En cambio, restaba completar la reconstrucción de la bóveda de cañón que se proponía realizar el año anterior, operación que hacía preciso trazar sendos arcos de medio punto en sus extremos y un sistema de mampostería formada por "costillas" sobre el trasdós, a modo de compartimentos, que recibirían el macizado en el que descansaría el nuevo graderío. La idea era enlazar los sectores de graderío reconstruidos (Fig.6).

${ }^{88}$ BVAAFV. Obras de conservación en el Anfiteatro de Tarragona. Memoria. Signatura 953. 8 de junio de 1970.

${ }^{89}$ BVAAFV. Obras de conservación en el Anfiteatro Romano de Tarragona. Memoria. Signatura 954. 21 de mayo de 1971.

${ }^{90}$ BVAAFV. Obras de conservación en el Anfiteatro Romano de Tarragona. Memoria. Signatura 955. 13 de abril de 1972. 


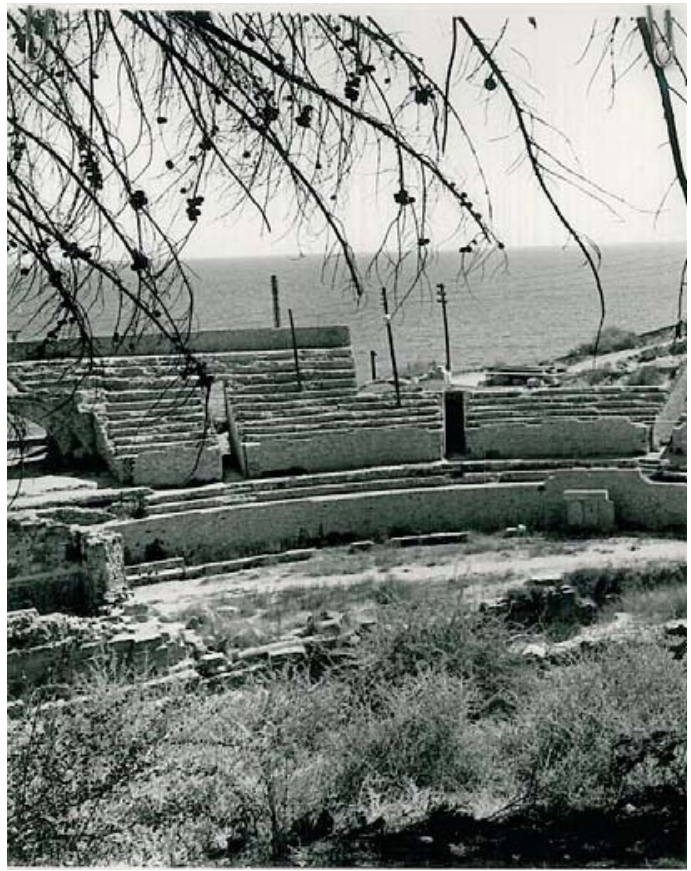

- Fig. 6 Tramo de graderío a reconstruir, para enlazar lo conservado y lo rehecho. Biblioteca Valenciana. Archivo Alejandro Ferrant Vázquez. Obras de conservación en el Anfiteatro Romano de Tarragona. Memoria. Signatura 955. 13 de abril de 1972.

Como colofón a todas estas intervenciones de Alejandro Ferrant, se consolidó una estructura muy distinta de las ruinas conservadas antes de iniciarse el proceso de restauración del conjunto (Fig.7).

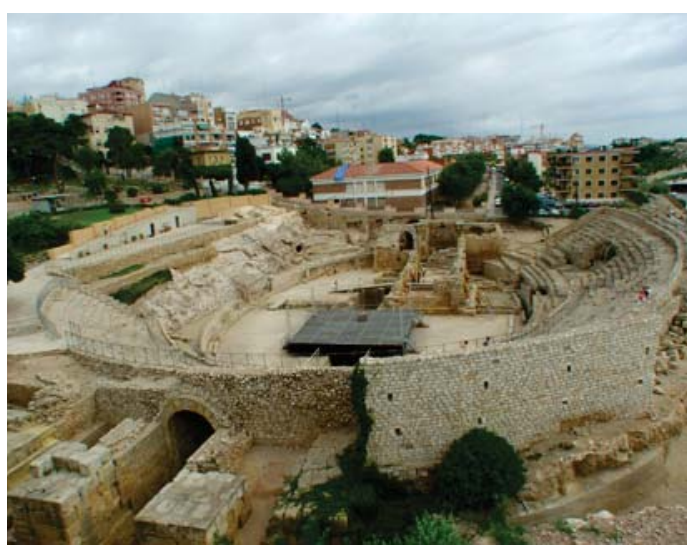

- Fig. 7 Imagen actual del anfiteatro de Tarragona, siendo visible el acceso y las dependencias laterales y la zona del graderío, a la derecha, reconstruidos por Alejandro Ferrant. Foto de la autora
ACTUACIONES EN EL FORO ROMA$\mathrm{NO}$

Con motivo de las obras de apertura de varias calles a finales del siglo XIX, se produjeron una serie de descubrimientos arqueológicos y en 1925 miembros de la Sociedad Arqueológica depositaron en el Museo de Tarragona algunos de los elementos localizados. La Comisión Provincial de Monumentos defendió el interés del yacimiento y cuando en 1928 Joan Serra i Vilaró fue nombrado Delegado de la Junta Superior de Excavaciones, inició una intensa labor de investigación y de lucha por su restauración. Como arquitecto de la cuarta zona, Alejandro Ferrant fue el encargado de llevar a cabo esos trabajos, que se iniciaron en 1955 y continuaron en diferentes campañas a lo largo de los años sesenta ${ }^{91}$. En 1966, Ferrant señalaba que el largo abandono del yacimiento hacía más dificultosa la labor, pues muchos de los restos que aparecían en el plano de Serra i Vilaró (Fig.1), eran difíciles de identificar ${ }^{92}$. La recuperación del foro tarraconsense no fue fácil. La falta de civismo hizo que muchos vecinos arrojasen sobre las ruinas todo tipo de inmundicias y el Ayuntamiento intentó paliar el problema en 1965 disponiendo las pantallas que aislaban el conjunto de las fachadas del entorno (Fig. 8). Incluso se llegó a plantear remover los restos y trasladarlos a otro espacio y dedicar sus solares a la construcción, aunque finalmente esa disparatada idea quedó olvidada y el Estado adquirió los terrenos para solventar toda tentación posterior de especulación en ese espacio ${ }^{93}$. A partir de 1966, los trabajos de recuperación del mismo se intensificaron y poco a poco consiguieron ponerlo en valor.

91 BVAAFV. Obras de conservación del foro romano. Memoria. Signatura 970. 5 de mayo de 1955.

${ }^{92}$ BVAAFV. Obras de conservación en el Foro Romano de Tarragona. Memoria. Signatura 970.5 mayo de 1966.

93 BVAAFV. Obras de conservación. Memoria. Signatura 973.10 abril de 1969. 


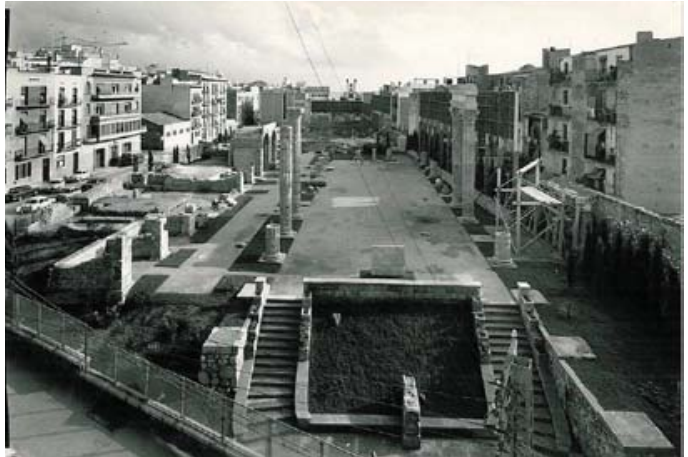

- Fig.8 Estado del foro tras la segunda fase de las restauraciones, con los elementos reconstruidos y la zona de acceso. Biblioteca Valenciana. Archivo Alejandro Ferrant Vázquez. Foro Romano de Tarragona. Obras de conservación. Memoria. Signatura 974. 13 de abril de 1970.

La compleja restauración del foro tarraconense se reseña en el informe del arqueólogo Alberto Balil de 20 de noviembre de $1966^{94}$. Balil explicaba que el yacimiento ocupaba dos solares separados por una calle y que ambos espacios presentaban similares problemas de conservación, aunque sus materiales de construcción eran diferentes, puesto que en el foro se emplearon sillares y sillarejo y en la zona comercial primaban el adobe y el tapial. Se trataba de llevar a cabo una intervención que respondiera a tres objetivos: acondicionamiento y presentación de los restos, valoración urbanística de los mismos y saneamiento del sector.

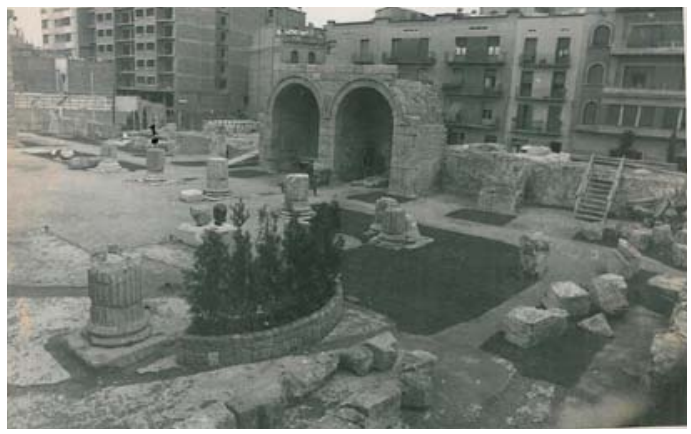

- Fig. 9 Estado del foro tras la primera fase de restauraciones, sin las columnas rehechas, pero con la jardinería y el busto de Serra i Vilaró. Es

${ }^{94}$ BVAAFV. Informe sobre la visita realizada el 20 de febrero de 1966 al foro de Tarragona y posibles trabajos de conservación y restauración del mismo. Signatura 970. visible el edificio en construcción que altera el entorno del yacimiento. Biblioteca Valenciana. Archivo Alejandro Ferrant Vázquez. Foro Romano de Tarragona. Obras de conservación. Memoria. Signatura 974.13 de abril de 1970.

En cuanto al primer objetivo, se proponía una anastilosis mínima (Fig.9), colocando los tambores sobre las basas, sin recurrir a la reconstrucción, salvo discretos recrecidos de los muros, puesto que no había elementos suficientes para hacerla con cierta seguridad. No se consideraba honrado elaborar un "costoso e hipotético pastiche" y se primaba la conservación de las ruinas ${ }^{95}$. El segundo objetivo, la valoración urbanística del foro, había sido debatido en la comisión de especialistas y se trataba de un problema complejo, puesto que se encontraba rodeado de viviendas, cuyas medianeras ofrecían un pobre aspecto (Fig. 10). La idea de expropiarlas y derribarlas para adecuar el entorno del yacimiento se barajó, pero se impusieron las limitaciones económicas y se optó por dedicar a intervenciones en el patrimonio tarraconense parte de los fondos que hubiera sido necesario invertir en indemnizaciones y derribos y ocultar las medianeras mediante jardinería ${ }^{96}$. Balil advertía que debía controlarse la especulación e impedir nuevas construcciones en el entorno cuando desaparecieran esas edificaciones, a las que auguraba una "corta vida", dada su mala calidad, pero apenas se habían culminado las obras de restauración del conjunto, se estaba construyendo en sus inmediaciones un nuevo bloque de viviendas, que hoy se mantiene en su lugar (Fig.9). Otro aspecto no menos importante era el relativo a la conservación y limpieza. El Ministerio no podía hacerse cargo de esa tarea y pedía con insistencia al Ayuntamiento que asumiese sus responsabilidades. Un problema técnico específico era el de la conservación de las estructuras de tapial y adobe, y se sopesaba utilizar para su consolidación silicatado o resinas sintéticas.

\footnotetext{
${ }^{95}$ Ibídem, p. 2.

${ }^{96}$ Ibídem, p. 1.
} 


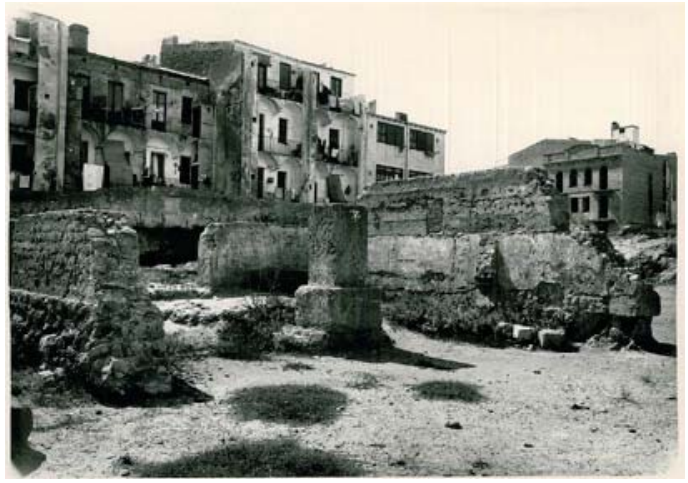

- Fig. 10 Imagen del foro de Tarragona antes de las restauraciones. Estado de abandono y pobre aspecto de las fachadas de las casas circundantes. Biblioteca Valenciana. Archivo Alejandro Ferrant Vázquez. Obras de conservación en el Foro Romano de Tarragona. Memoria. Signatura 970. 5 mayo de 1966.

Ferrant debía adecuar sus sucesivos proyectos de restauración a lo propuesto por la comisión asesora. La anastilosis de las columnas hacía necesario reproducir su organización en planta para rehacer sus asientos, de tal manera que se diera una idea de la forma original del edificio y se pudieran recolocar algunos de los soportes, sugiriendo sus proporciones ${ }^{97}$. También se reintegraría al conjunto la columna que había sido trasladada al Paseo Arqueológico y se recuperarían piezas depositadas en el Museo. El proceso se completaría con el añadido de elementos faltantes, para los que se emplearía el mismo material que el original, pero diferenciándolo, respetándose de esa forma el principio de la notoriedad de la intervención. Se trata de una restauración arqueológica en sentido estricto.

La intervención fue acompañada de nuevas investigaciones arqueológicas y Ferrant solicitaba la presencia de Balil, convencido de que todo lo recuperado debía analizarse para decidir si era posible su respetuosa, aunque conjetural, reconstitución, siempre dentro de los límites impuestos por los especialistas, para lo que proponía: elevación somera de los muros de las casas con

${ }^{97}$ BVAAFV. Obras de conservación en el Foro Romano de Tarragona. Memoria. Signatura 970. 5 mayo de 1966. fábrica de mampostería; disponer en algunos lugares sobre los cimientos o improntas de los zócalos unos pedestales que recordasen el ornato de la calle; presentar las piezas recuperadas en su lugar; recuperar la conducción o cloaca de la que se conservaban tramos; buscar los niveles de los pisos de las casas para disponer hormigonado o empedrado, según los casos, teniendo en cuenta que su disposición y aspecto armonizasen con los restos del pavimento antiguo y añadir zonas vegetales en las partes no excavadas para integrarlas discretamente con los restos arqueológicos ${ }^{98}$ (Fig.9).

La inauguración oficial del conjunto tuvo lugar el 9 de noviembre de 1968, instalándose asimismo un busto de Serra i Vilaró, obra del escultor Joan Salvador i Voltes, que sustituyó a uno anterior, desaparecido en el transcurso de la guerra civil. Pero esa inauguración no significó que se dieran por concluidas las intervenciones. En 1969 Alejandro Ferrant se mostraba descontento con los resultados, señalando que eran pobres $^{99}$, ya que la escasa elevación de los recrecidos llevados a cabo y lo reducido de los fragmentos arquitectónicos hallados y recuperados, impedía reflejar la envergadura original del conjunto (Fig.9). Por ese motivo, proponía crear unos elementos de referencia, reproducciones en piedra artificial de basas, fustes y capitel, reintegrando en ellas fragmentos originales de cornisas y arquitrabe, y reconstruir dos columnas completas y el entablamento correspondiente, proporcionando al visitante una idea más exacta de la monumentalidad que había tenido el edificio. Además, el recinto había quedado más elevado que las calles abiertas en su entorno y era necesario construir una escalinata de acceso al mismo (Fig. 8). Estas

${ }^{8}$ BVAAFV. Obras de conservación en el foro romano de Tarragona. Construcciones anexas. Memoria. Signatura 971. 14 de junio de 1967 y Archivo General de la Administración (en adelante AGA). Cultura. Signatura (3) 115. Caja 26/00119.

99 BVAAFV. Obras de conservación 1969. Memoria. Signatura 973. 10 abril de 1969. 
intervenciones se prolongaron en $1974^{100}$, cuando se daba cuenta de que las ruinas ya habían sido "ordenadas, reconstruidas y reproducidas".

\section{ACTUACIONES EN EL PRETORIO O PALACIO AUGUSTO, MURALLAS Y RESTOS DEL CIRCO}

El edificio que hubo de ser residencia del pretor romano fue construido en el siglo I a. C. y había llegado a los años cincuenta del siglo XX con evidentes transformaciones. Según Alejandro Ferrant, del conjunto original se había conservado una cuarta parte. Las sucesivas campañas de excavación y restauración fueron dejando al descubierto restos de la estructura original ${ }^{101} \mathrm{y}$, en un primer momento, el objetivo de las intervenciones en el pretorio era recuperar las estructuras romanas y medievales y que el edificio pudiera servir como un "complemento" del Museo Arqueológico.

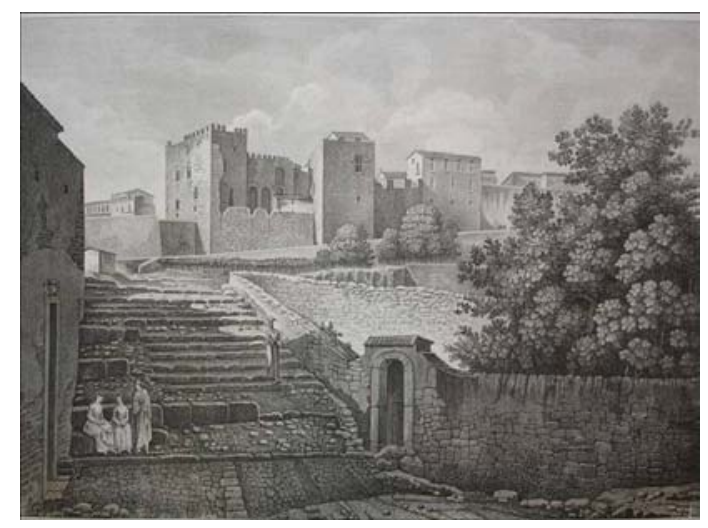

- Fig. 11 A Grabado que muestra el estado del pretorio y la muralla de Tarragona sobre 1820, antes del proceso de restauración, con las murallas, las arquerías y los edificios adosados sobre la zona que actualmente ocupa el museo. A. LABORDE, Voyage Pittoresque et Historique de L'Espagne.

${ }^{100}$ BVAAFV. Obras de conservación 1970. Memoria. Signatura 974. 13 de abril de 1970.

${ }^{101}$ BVAAFV. Obras de conservación en la Plaza del Rey del palacio Pilatos de Tarragona. Memoria. Signatura 999. 27 junio de 1972.
Las labores de excavación se iniciaron en $1957^{102}$ y continuaron en $1958^{103}$. Las obras de derribo de las edificaciones añadidas habían dejado al descubierto los restos de lo que se suponía la residencia del pretor, almenas y una ventana gótica cegada, resultado de las reformas medievales del edificio. Se inició una labor compleja de eliminación de todos aquellos estratos arquitectónicos que no se consideraban "originales" (Fig.11) y que Ferrant señala que debía de acompañarse de los correspondientes estudios para discernir ese punto. La destrucción de todos esos aditamentos debía completarse con las excavaciones tanto en el interior del edificio como en la plaza del Rey. Ferrant refería que en el conocido grabado de Laborde (Fig.11) aparecen unas arcadas que a su entender podían corresponderse con dos arcos conservados y proponía derruir el macizo que en ese momento estaba situado bajo ellos en busca de más restos que pudieran considerarse originales. También consideraba necesario vaciar la gran masa de tierra y piedra que ocupaba el espacio de lo que había sido cárcel, para localizar la gran sala de la planta baja, o en su defecto cimientos $\mathrm{u}$ otros elementos que pudieran relacionarse con la misma. Estas operaciones continuaron en años sucesivos y fueron apareciendo la puerta de la fachada de la plaza del Rey y el patio medieval donde se pretendía descubrir el aljibe enterrado hasta aquel momento. También se recuperaron el arranque de los pilares del pórtico de tres arcos de medio punto dibujado por Laborde (Fig.11) y parte de la muralla dispuesta oblicuamente ante el palacio. Ferrant achacaba el complejo estado del conjunto a la voladura que había sufrido durante la guerra de la independencia y afirmaba que la alteración que había supuesto esa destrucción obligaba a "realizar un minucioso estudio arqueológico para determinar, por medio de una estratigrafía las épo-

102 AGA. Cultura. Signatura (3) 115. Caja 26/00309. Obras de Exploración en el Pretorio o Palacio de Augusto de Tarragona. Memoria. 5 agosto de 1957.

${ }^{103}$ BVAAFV. Palacio de Pilatos. Obras de excavación. Memoria. Signatura 989. 9 julio de 1958. 
cas distintas de los terrenos que por las catas practicadas van apareciendo, así como de las monedas y objetos que entre los escombros se van hallando" ${ }^{104}$.

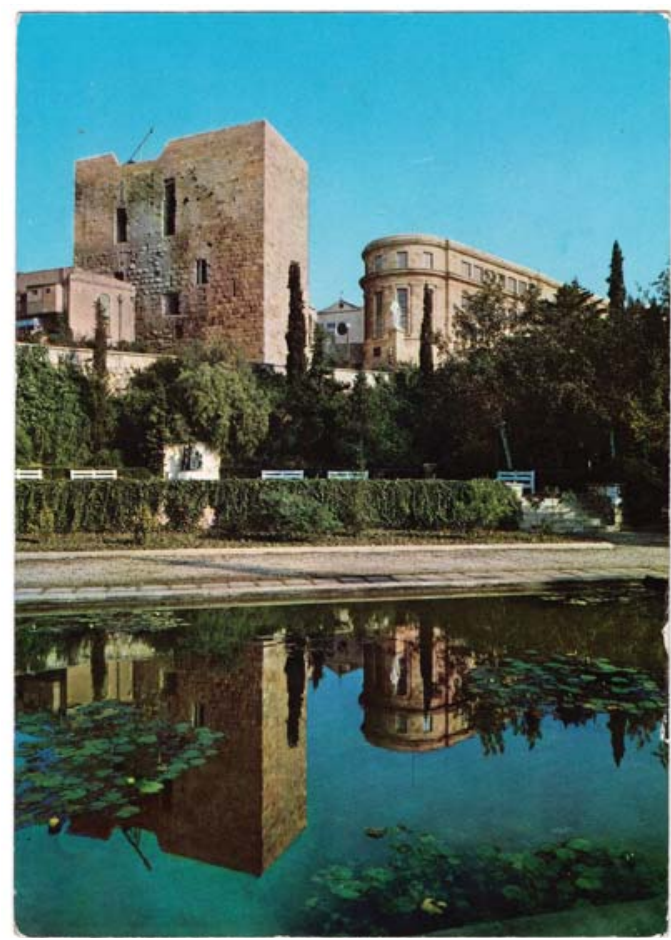

- Fig. 11 B Estado del pretorio en los años setenta del siglo XX. Han desaparecido muros y construcciones adosadas $\mathrm{y}$ ha sido construido el Museo Arqueológico. Foto de la autora.

Poco a poco, los diferentes estratos históricos fueron desvelados y en 1960 se iban perfilando ${ }^{105}$. En algún caso, los elementos sustentantes aparecían faltos de fundamento y Ferrant anticipaba que sería necesario llevar a cabo labores de apeo de los mismos y desmontarlos para proceder a su correcta reconstrucción. La prioridad era la conservación de los vestigios romanos y medievales, lo que suponía relegar los restantes añadidos del monumento. Ese fue el caso de las fachadas que miraban al Mediterráneo, que en su zona baja formaban parte del

${ }^{104}$ BVAAFV. Obras de exploración y excavación (I). Memoria. Signatura 990. 30 junio de 1959

105 BVAAFV. Obras de exploración y excavación (II). Memoria. Signatura 991. 13 septiembre de 1960. lienzo de muralla de época moderna y cuyo basamento era un muro de contención que unía el pretorio con el tramo defensivo que se emplazaba en el solar del Museo Arqueológico (Fig.11). Al derribar las fachadas superiores, se esperaba localizar los restos de la muralla romana. Ferrant precisaba que estas intervenciones se llevarían a cabo con la dirección de un arqueólogo, la supervisión constante de un ayudante del mismo y un equipo competente y con la elaboración de una estratigrafía, dado que el solar del pretorio permitía hacer un seguimiento de los diferentes niveles históricos desde la época romana a la medieval. Se pretendía también fechar la construcción romana.

Estas labores arqueológicas dieron como resultado un informe elaborado por la Comisaría de Arqueólogos nombrada por el Ministro de Educación Nacional el 25 de enero de 1962 y que fue la base del proyecto firmado por Ferrant en mayo de ese mismo año ${ }^{106}$. El informe proponía: el derribo del cerramiento levantado ante el edificio y orientado al paseo de San Antonio, con la intención de dejar al descubierto la muralla romana; la construcción parcial de la fachada y la excavación arqueológica, que debía de ser llevada a cabo por Alberto Balil Illana, encargado de las intervenciones en las zonas del pretorio donde se hubiese localizado obra de época romana. Se precisaba que la demolición del cerramiento de época moderna, al que se consideraba falto de valor, se haría recuperando todos los elementos que pudieran clasificarse como romanos y que éstos serían reutilizados en el proceso de restauración. La fachada reconstruida se enlazaría con la que presentaba el pretorio, de manera que se garantizase la trabazón entre ambas. A falta de indicios de cómo habría podido ser ese frente en etapas anteriores, se conservarían los huecos que presentaba, siempre que facilitasen la iluminación de las salas que se iban a disponer dentro del edificio. Se trató de una intervención en la que el grado

${ }^{106}$ BVAAFV. Obras de restauración y excavaciones. Memoria. Signatura 993. 24 de mayo de 1962. 
de reposición de sillares fue muy alto, puesto que se consideró que estaban muy degradados, aunque se intentó recuperar el mayor número de materiales originales posible. En las zonas rehechas se utilizó piedra de canteras próximas a Tarragona, de análoga calidad y color que la original, pero descartando volver a utilizar esa misma, que procedía de la cantera romana de Médol, debido a su fácil degradación. Se perseguía, por tanto, la unificación visual y de textura de la fachada rehecha.

La siguiente fase de intervenciones se propuso en $1963^{107}$. En la memoria Ferrant señala que fue necesario recalzar la fachada al paseo de San Antonio, en su ángulo con la calle de las Escaleras, además de proceder a consolidar y atirantar el muro, dado su mal estado, proponiendo que esas operaciones se extendiesen a la zona de coronación del edificio. También afirmaba que debía rehacerse la cubierta porque estaba muy degradada, utilizando para ello hormigón armado, forjado cerámico y pavimento de losas de Vendrell. Disponer esta nueva estructura suponía introducir materiales contemporáneos en el monumento e hizo necesario desmontar la terraza existente y su pretil.

El proceso de eliminación de todo aquello que se consideraba un añadido falto de valor continuó en siguientes fases de restauración. En 1964, Ferrant proponía seguir demoliendo estructuras, tras haberse efectuado un estudio estratigráfico de las tierras que se habían ido depositando en la zona del patio, lo que hacía necesario desmontar el gran arco ojival se que apoyaba en ellas ${ }^{108}$. Se eliminaron todas las transformaciones correspondientes con los sucesivos cambios de usos del edificio y que "desfiguraban" las construcciones medievales. Como, además, a juicio de Ferrant se habían conservado elementos suficientes para una "respetuosa restauración", fueron rehechos los tres ven-

${ }^{107}$ BVAAFV. Obras de conservación. Memoria. Signatura 994. 29 abril de 1963.

${ }^{108}$ BVAAFV. Obras de conservación. Memoria. Signatura 995. 24 febrero de 1964. tanales góticos. Este proceso era considerado como una "reordenación" de la fachada y la reapertura y cierre de vanos como "rectificaciones". Asimismo, se propuso el vaciado de tierras de la calle de las Escaleras, descubriendo la zona baja de la fachada del Pretorio a la misma, donde se preveía encontrar los restos de bóvedas, que se esperaba comunicasen con las correspondientes al circo, como así fue finalmente. El plano que se adjunta en el proyecto delimita mediante diferentes colores el complejo proceso de relectura y repristinación de la fachada a la calle de las Escaleras. Ferrant da muestra de la pervivencia del método de documentación científica aprendido en su fase de formación como arquitecto de la primera zona, pero recurre a una metodología propiamente restauradora que consideraba conveniente en un monumento de alto valor arqueológico.

En 1965 se esbozaban las intervenciones que pondrían fin al proceso de restauración, y que incluían operaciones como la colocación de cerramientos y vidrieras en los vanos o la disposición de puertas en los accesos desde la calle de las Escaleras y a las nuevas salas ${ }^{109}$. La portería debía de estar en "armonía con el carácter del edificio" y lo mismo se precisaba respecto al envigado de las diferentes dependencias, como la llamada Sala Romana de la planta baja. Los matices que debían diferenciar los espacios de época romana se precisaban claramente: envigado recio, portería sencilla y solado de enlosado de piedra, mientras que para el resto de los espacios se utilizaría otro de tipo cerámico o continuo. La comunicación entre los distintos niveles se haría mediante una escalera de viguería de hierro y barandilla del mismo material y muy simple, con escalones de madera.

El 19 de febrero de 1966, Alberto Balil efectuó una visita de inspección, certificando que los trabajos desarrollados cumplían el objetivo de destinar el monumento a un fin museístico y al mismo tiempo poner de

${ }^{109}$ BVAAFV. Obras de terminación. Memoria. Signatura 996. 17 de marzo de 1965. 
manifiesto el valor de sus estructuras romanas y medievales, que con la restauración quedaban, a su entender, debidamente realzadas $^{110}$. Balil aconsejaba nuevos trabajos de demolición de las estructuras más recientes, como el muro situado en el lado SE del Museo Arqueológico (Fig. 11), y cuya función había sido enlazarlo con otro, que consideraba decimonónico, que partía de la Torre y que ya había sido demolido. Las palabras del arqueólogo precisan lo que consideraba respetar la historia del monumento al referir que la opción de conservar las fases romana y medieval suponía "restituir el edificio a su forma y destinación prístina pero sin prescindir de las estructuras medievales que no solo lo embellecen sino que documentan su historia". Con esos objetivos, el muro inmediato al museo era prescindible, $\mathrm{y}$ con él el basamento de la estatua de Augusto, obra del escultor Viladomat, que debería instalarse en otro lugar. A juicio de Balil, el muro empequeñecía al museo y al pretorio y ocultaba una parte del mismo. En su lugar, consideraba adecuado prolongar la zona de césped y enrejado que se había dispuesto en el SE y proceder al chapado de la cimentación de la rotonda del edificio del museo, ocultando su encofrado de hormigón. Esas intervenciones proporcionarían, a su entender, un presentación más adecuada del monumento, su mejor encuadre urbanístico y un embellecimiento de la ciudad (Fig.11).

También recordaba Balil que la comisión nombrada por el Ministerio en 1962 para establecer las directrices que debían regir la restauración, había determinado efectuar excavaciones junto a su fachada norte. Pero parece que esa intervención había sido decidida en una reunión a la que Francisco Íñiguez, Comisario General del Servicio de Conservación del Patrimonio Nacional, no había asistido y que posteriormente Íñiguez había transmitido a Balil, que era el secretario de la Comisión, que se oponía a esa ex-

${ }^{110}$ BVAAFV. Informe sobre la visita realizada el 19 de febrero de 1966 al monumento nacional de Tarragona conocido con el nombre de Torre de Pilatos y plan de los futuros trabajos de excavación. Signatura 996. cavación, ya que consideraba que no debía llevarse a cabo sin que lo requiriera la actividad restauradora. Balil se mostraba igualmente partidario de esa reserva, pero explica en su informe que aceptó la propuesta porque, como defendían los restantes miembros de la Comisión (Ferrant, Batle, Navascués, Ventura y Serra i Vilaró) era imposible restaurar el monumento sin llevar a cabo intervenciones arqueológicas, ni relacionarlo con el conjunto de los restos romanos de Tarragona. Esa idea quedó confirmada, a juicio de Balil, tras sus excavaciones de 1962 y 1963 y con los intercambios mantenidos con Alejandro Ferrant, de manera que el diálogo entre los arqueólogos y el arquitecto restaurador fue dando respuesta a los diferentes problemas que el conocimiento y la restauración del monumento iban planteando. Es este el mismo procedimiento que Ferrant había aplicado en sus años de formación junto a Manuel Gómez-Moreno.

Otro aspecto muy interesante del informe es el relativo a la relación entre el pretorio y las bóvedas del circo. Se reseña que las graderías del circo habían sido identificadas en el siglo XVII, afectadas por la voladura de 1814 y por el urbanismo decimonónico y posteriormente olvidadas, siendo redescubiertas por las investigaciones llevadas a cabo por Miguel Aleu. Según Balil, era posible hacerlas visitables y aunque su restauración podría ser costosa, la recuperación de los $800 \mathrm{~m}^{2}$ que abarcaban esas bóvedas que formaron parte del circo, incorporarían al Patrimonio Artístico Nacional un conjunto monumental "sin par en el mundo romano" y asegurarían, más allá de toda previsión, nuevos espacios al Museo Arqueológico de Tarragona. En el aspecto de la tutela, también se señalaba la falta de protección expresa de los restos del circo, que en ese momento estaban incluidos, eso sí, en la declaración monumental de la ciudad, y que esa falta de protección individualizada había permitido que una parte de las antiguas bóvedas de las galerías hubieran sido habilitadas para uso comercial en 1963. En opinión de Balil, su 
recuperación impediría que pudieran repetirse hechos semejantes.

En 1970 se daba cuenta de la puesta en valor que había supuesto el proceso previo y de que interés del pretorio y de sus restos romanos y medievales parecía fuera de toda duda ${ }^{111}$. En 1971 Alejandro Ferrant presentó un nuevo proyecto de intervenciones para recuperar los restos romanos hallados en las excavaciones de la plaza del Rey, fundamentalmente con el objeto de reconstruir los muros y bóvedas y de plantear una posible comunicación de las mismas con el Museo Arqueológico mediante una escalera descubierta ${ }^{112}$. Estos trabajos se continuaron en 1972, cuando ya se habían recuperado los muros almohadillados situados frente al museo, las bóvedas del circo que estaban bajo la plaza del Rey y que parecían continuar bajo la iglesia de la Santísima Trinidad y la puerta que se abría en los restos del circo y que se pensaba recuperar como paso entre éstos y el museo ${ }^{113}$. Para integrar los restos romanos, Ferrant proponía construir un muro de contención de las tierras que llenaban las bóvedas que no podían excavarse y uno de los pilares de cerramiento del museo y coronarlo mediante un pretil y una barandilla de hierro y piedra, que seguiría la línea de las bóvedas del circo y se cerraría en el edificio del pretorio. Tanto el recalce del museo como los senos de la bóveda romana, serían hormigonados, de manera que se introdujeron materiales contemporáneos en el yacimiento. Se proponía también continuar las excavaciones bajo el "atrio" del museo (Fig.12), delimitado por su reja de cerramiento, recuperar las piezas de interés, elaborar una estratigrafía y cubrir finalmente el espacio obtenido con un forjado pavimentado, de manera que el acceso al museo

${ }^{111}$ BVAAFV. Obras de conservación. 1970. Memoria. Signatura 997. 6 junio 1970.

112 BVAAFV. Obras de conservación. Memoria. Signatura 998. 18 de mayo de 1971.

${ }^{113}$ BVAAFV. Obras de conservación en la Plaza del Rey del palacio Pilatos de Tarragona. Memoria. Signatura 999. 27 junio de 1972. no fuera alterado, pero que en su subsuelo se mantuviera el espacio recuperado.

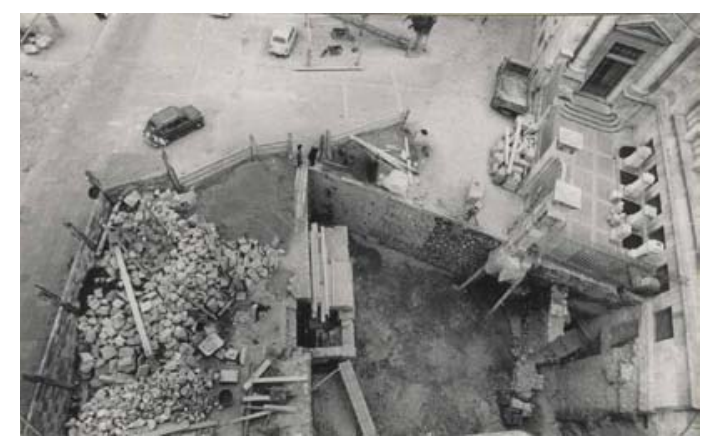

- Fig. 12. Excavaciones en la Plaza del rey y bajo el acceso al Museo Arqueológico, descubriendo parte de las bóvedas del circo romano. Archivo General de la Administración. Cultura. Obras de conservación en la Plaza del Rey del palacio Pilatos de Tarragona. Memoria. Sig. 26/00043. 27 junio de 1972.

En 1973 se hacían las propuestas para rematar estos espacios y enlazarlos con los restos de las bóvedas del circo, que a su vez se unían con el pretorio. El espacio creado integraría los restos hallados, pero tendría un solado de hormigón recubierto de terrazo en el resto del espacio, las paredes se pintarían y para la fachada del museo se utilizaría aplacado de piedra. También se pensó en la forma de articular el museo con el pretorio, que se había convertido en una prolongación del mismo. Para ello, Ferrant quería establecer un nexo mediante una reja de hierro que desde al atrio del museo llegara hasta el ángulo del pretorio, protegiendo el patio de la plaza del Rey. Además, se tuvieron en cuenta las posibilidades que la vista panorámica que podía disfrutarse desde la azotea del palacio de Augusto podían ofrecer a los visitantes y se proyectó una escalera que accediera a la misma desde el último piso, aunque ello alteraba el artesonado de la llamada Sala Gótica.

Todas estas complejas operaciones determinaron en buena medida el aspecto que el circo, el pretorio, la muralla y el museo tarraconsense presentan en la actualidad y han reelaborado su interrelación. 


\section{CONCLUSIONES}

A lo largo del tiempo, la ciudad de Tarragona ha mantenido una estrecha relación con los restos de su pasado romano, que han terminado por convertirse en una de sus señas de identidad y en uno de sus referentes patrimoniales más destacados. Las profundas transformaciones sociales y políticas de los últimos decenios no han supuesto una ruptura con esa tendencia, sino su afianzamiento. Ya hemos señalado el hito que supuso la integración de esos restos de la Tarraco romana en la Lista del Patrimonio Mundial, pero también puede constatarse que la memoria colectiva ha asumido y perpetuado las sucesivas lecturas ideológicas de esos testimonios del pasado. Sirva como ejemplo el caso de la pervivencia de hitos como las celebraciones relacionadas con la figura del emperador Augusto, recuperadas y recreadas con las iniciativas propuestas en torno al 19 de agosto de 2014, fecha en la que se cumplirán dos mil años de la muerte del emperador y setenta y cinco de la reposición de su efigie en el Paseo Arqueológico ${ }^{114}$. Tarraco Viva tie-

${ }_{114}$ Diari de Tarragona, edición de 24 de noviembre de 2013, consultado el 17 de julio de 2013, URL: http:// cultura.gencat.cat/bptarragona/recull/brscgi.exe?CMD $=$ VEROBJ\&MLKOB=12988344949. ne programados más de 800 actos entre los días 5 y 25 de mayo de 2014 y a través de ellos la ciudad revivirá nuevamente su relación con su pasado romano y sumará nuevos actos a esa tradición, incorporando una nueva lectura a la fuerte carga ideológica que los determinó en el pasado reciente ${ }^{115}$. No deja de resultar interesante constatar en el dossier de prensa de Tarraco Viva las nuevas connotaciones ideológicas que, inevitablemente, marcan los actos a celebrar ${ }^{116}$. Frente a la idea de la unidad española de la pasada conmemoración, se proponen ahora el ideal europeo y las ideas de la unidad mediterránea y de las raíces clásicas y mediterráneas de Cataluña. En cambio, se mantiene viva la identificación el pasado romano con la idea de civilización y cultura, mostrando la pervivencia de una visión marcadamente eurocentrista al señalar que la romanidad supuso la más brillante civilización de la Humanidad, olvidando, quizás, otras no menos singulares y brillantes. Ideología y patrimonio, al fin, siempre entrelazados y determinando la lectura del pasado romano de Tarragona.

115 Diario La Vanguardia, edición de 10 de febrero de 2014, consultado el 3 de marzo de 2014, URL: http://www.lavanguardia.com/local/tarragona/20140210/54401019092/actos-tarraco-vica-augusto. html .

116 “QQué conmemoramos? El éxito de una civilización que todavía hoy se percibe como la más brillante de la historia de la humanidad. Las raíces clásicas y mediterráneas de Cataluña. Un momento especialmente brillante en la cultura de la humanidad. El único momento en la historia del Mediterráneo en que todas sus riberas estuvieron unidas y con progreso, como no lo habían estado nunca hasta entonces. La creatividad de una cultura, la romana, que se convirtió en una civilización mediterránea. Una primera idea de Europa, basada en una red de ciudades enlazadas por vías terrestres y marítimas en torno al Mediterráneo". Dossier de prensa de Tarraco Viva, consultado el 3 de marzo de 2014, URL: http://www.tarracoviva.com/DATA/2014/2/95667_2014 _2_10_10_57_13_dosier_prensa_2014_.pdf . 